S3 File. HPLC and MS chromatogram of OMW samples.

SI_hydroxytyrosol (area=23514.1)

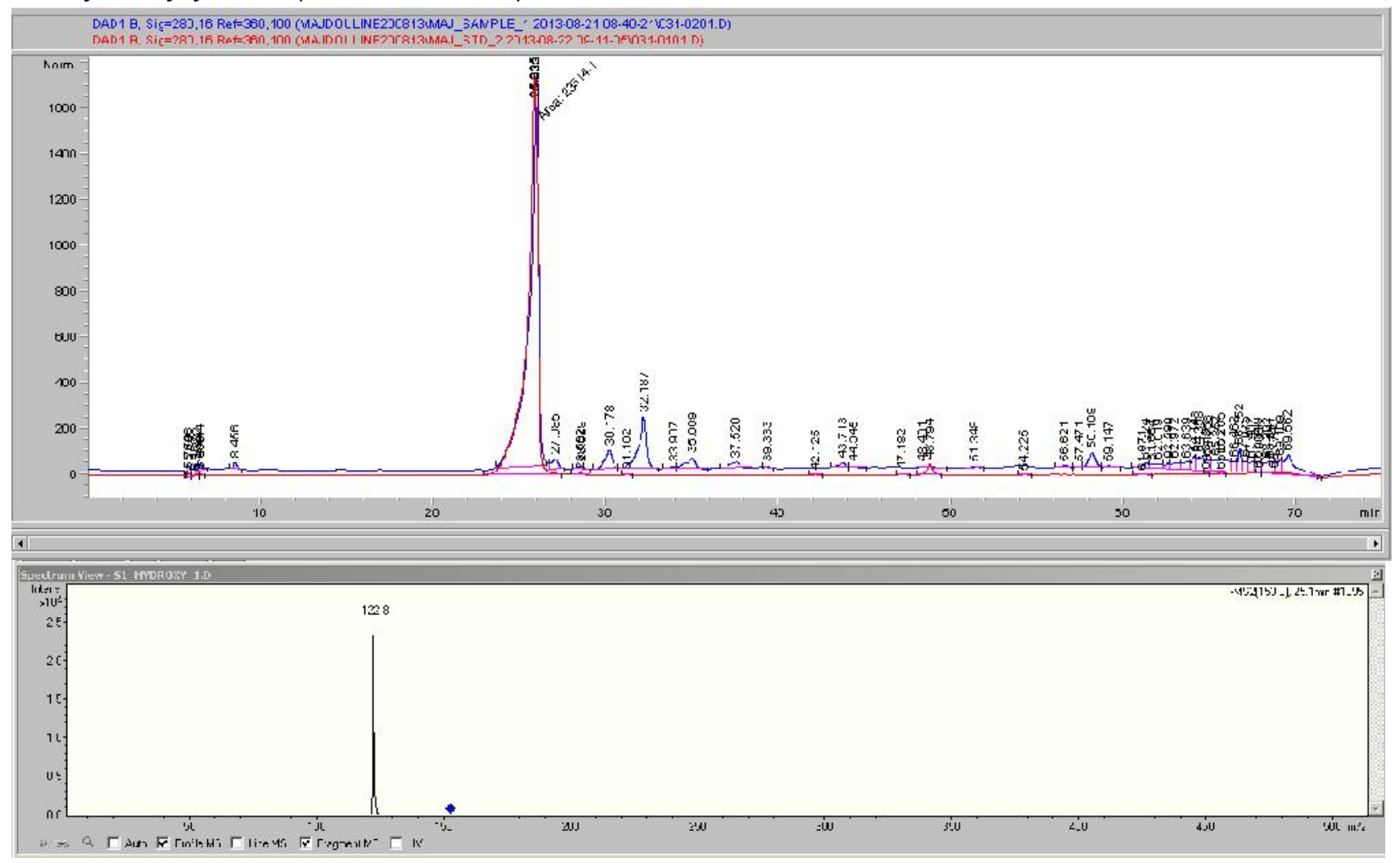

S1_Tyrosol (area=2351.81)

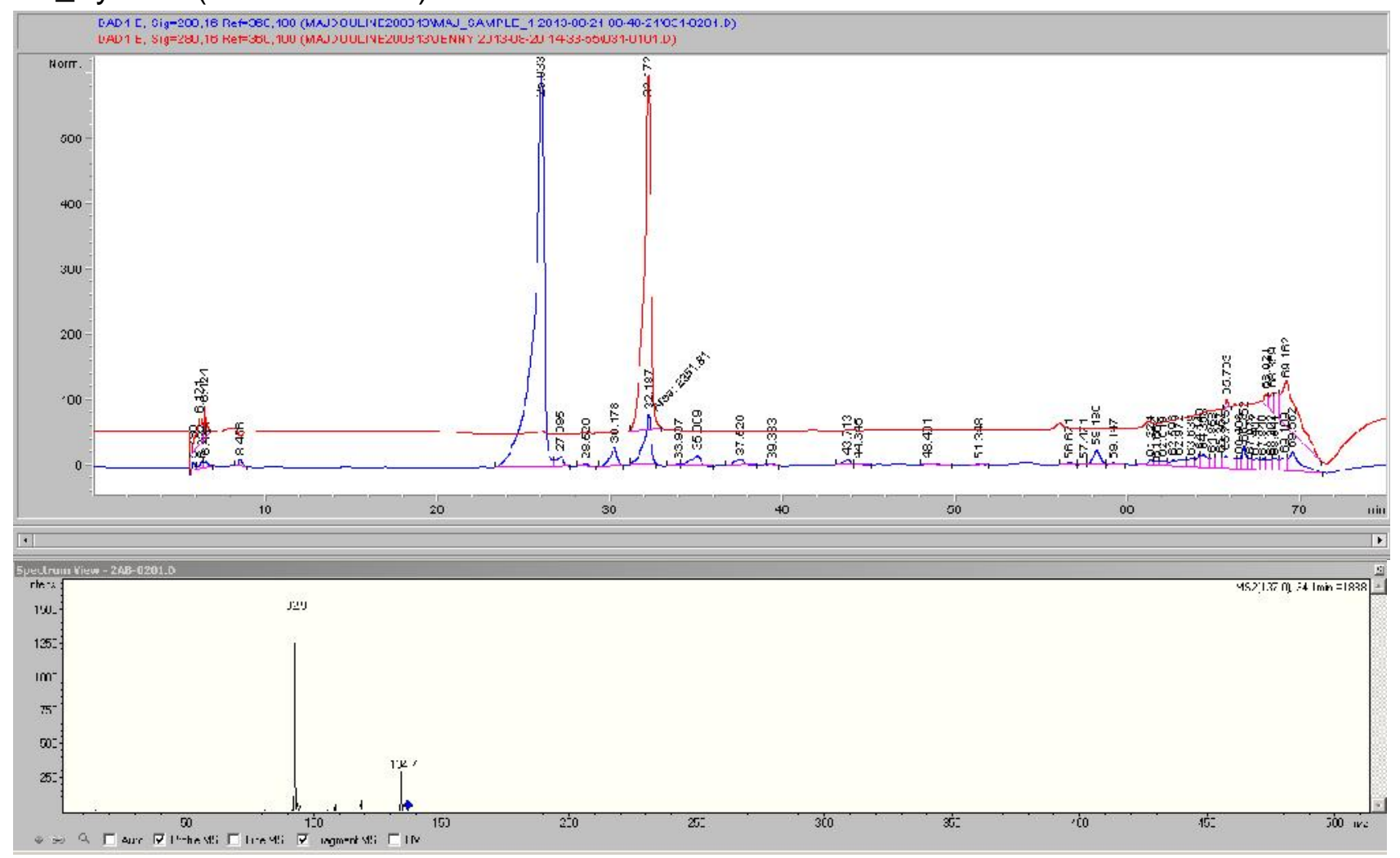


S1_Oleuropein (area=562.312)

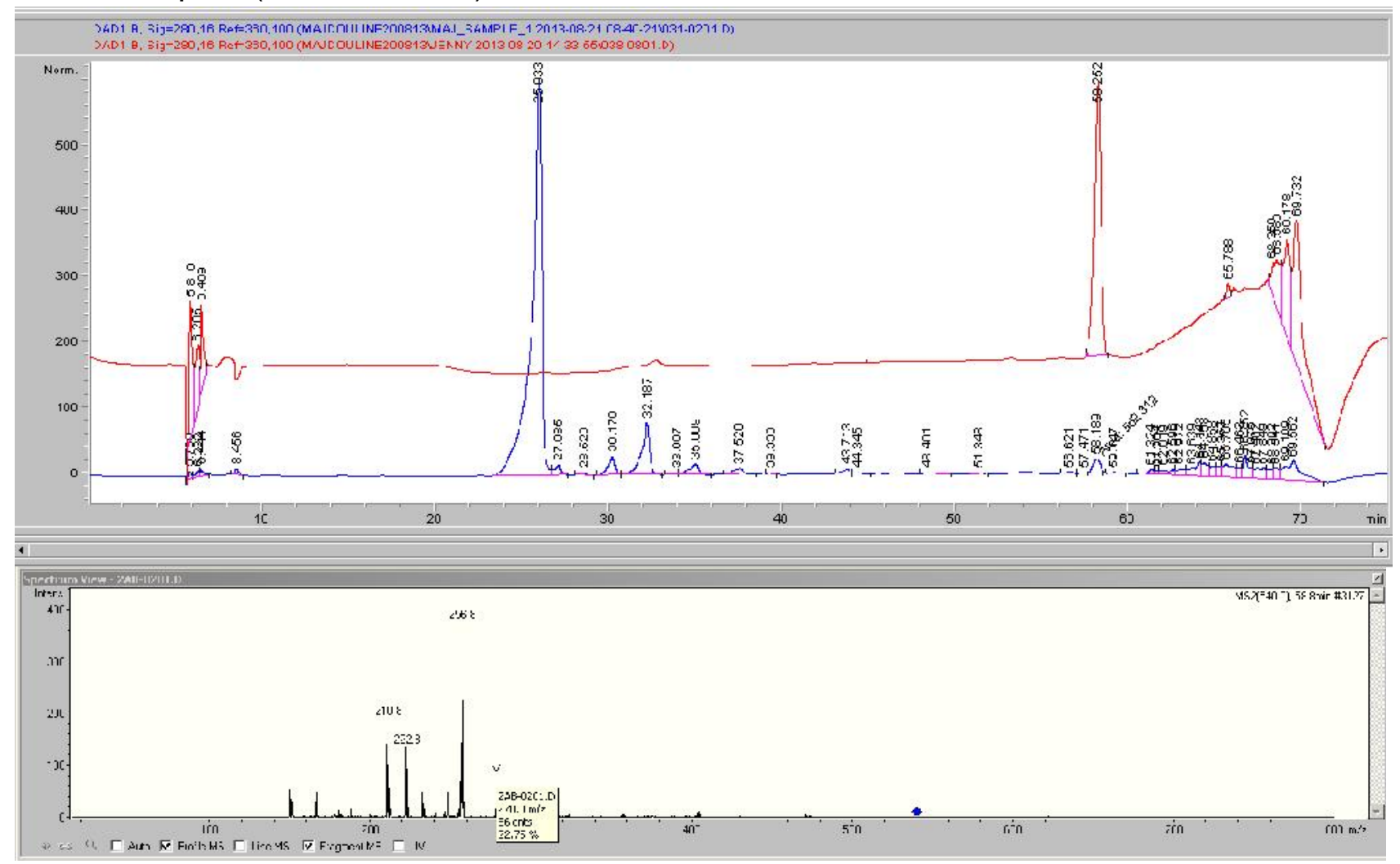

\section{S1_P-coumaric (area=72.3991)}

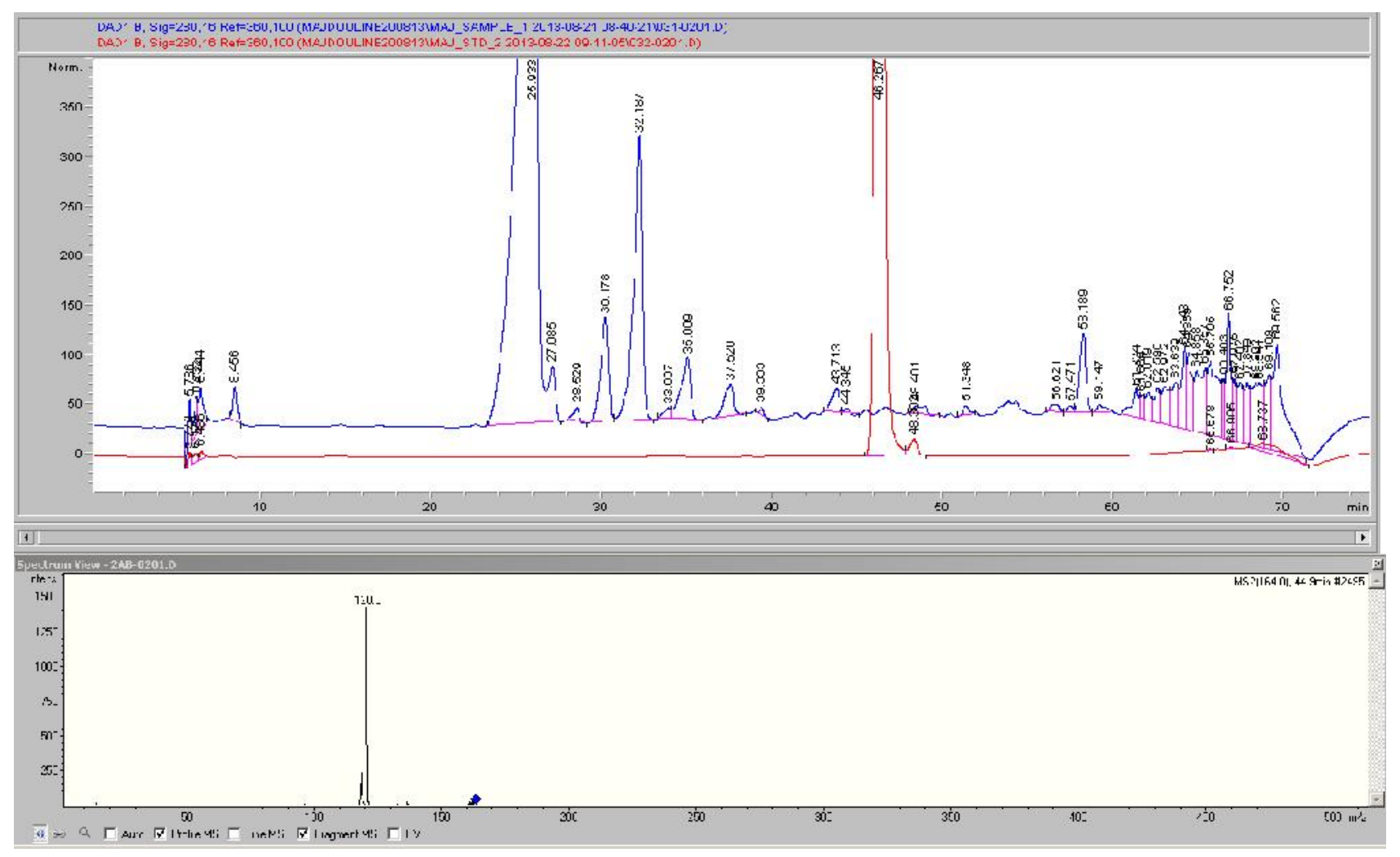


S2_Hydroxytyrosol (area=4024.34)

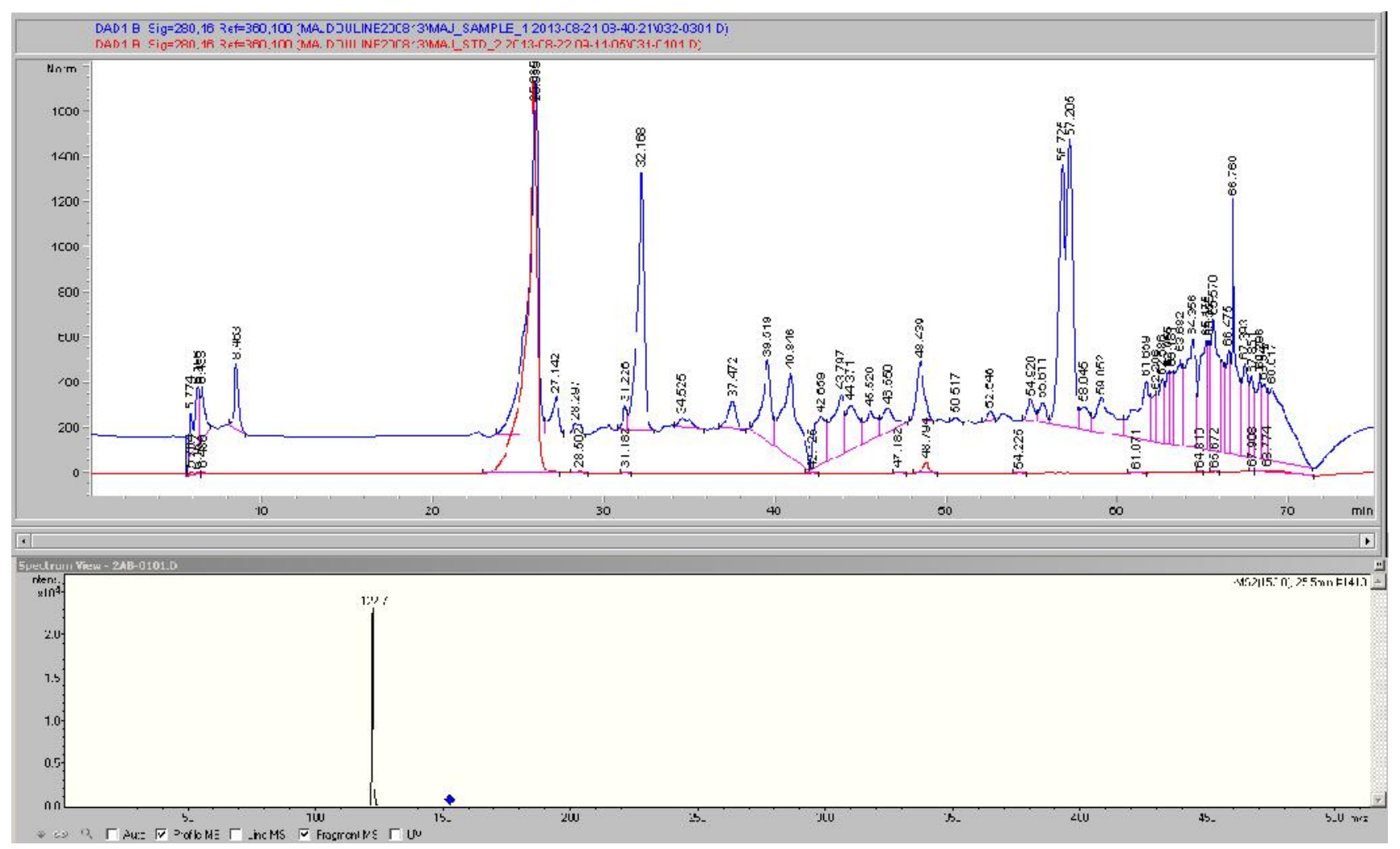

S2_Tyrosol (area=1999.67)

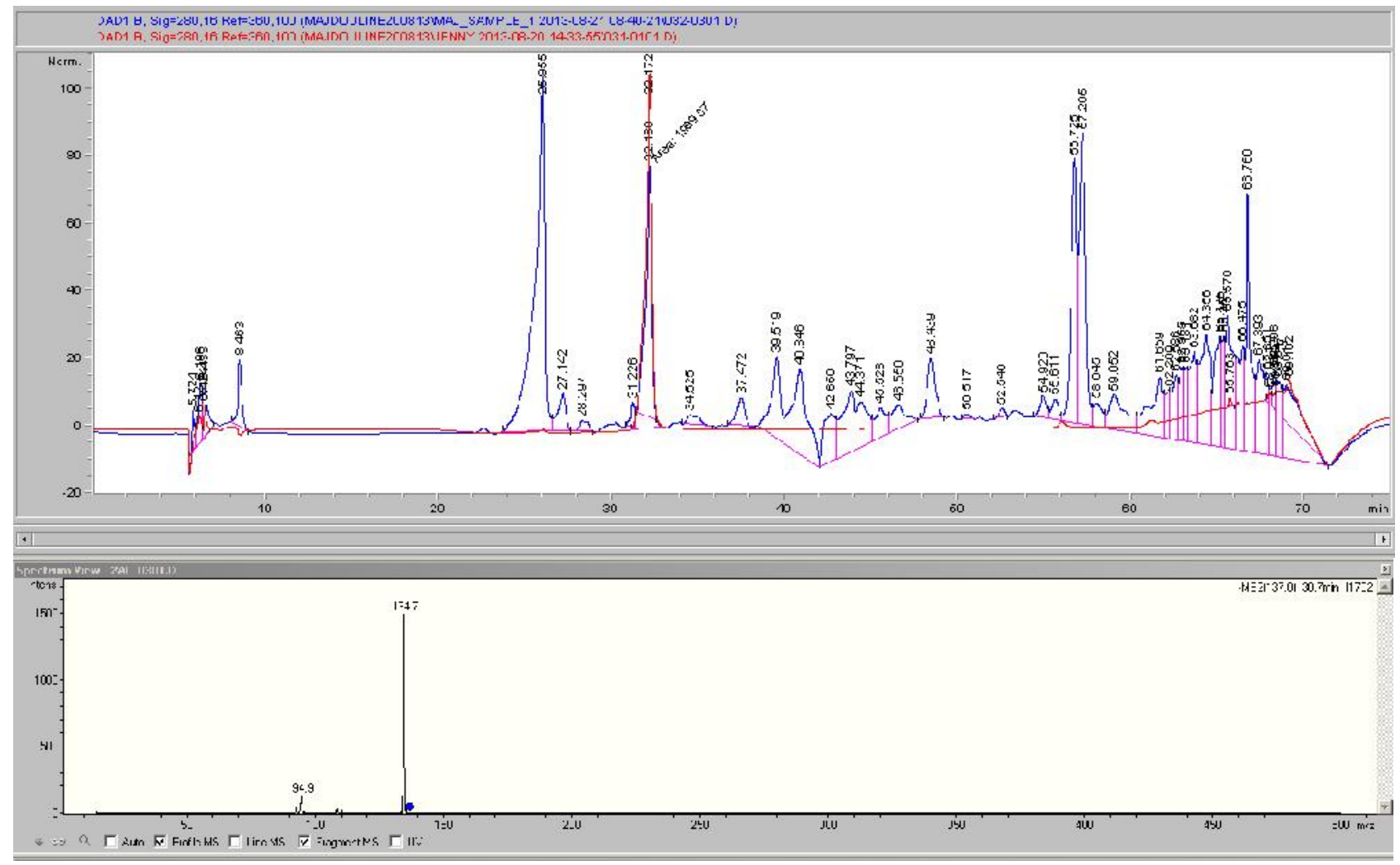


S2_Oleuropein (area=81.8678)

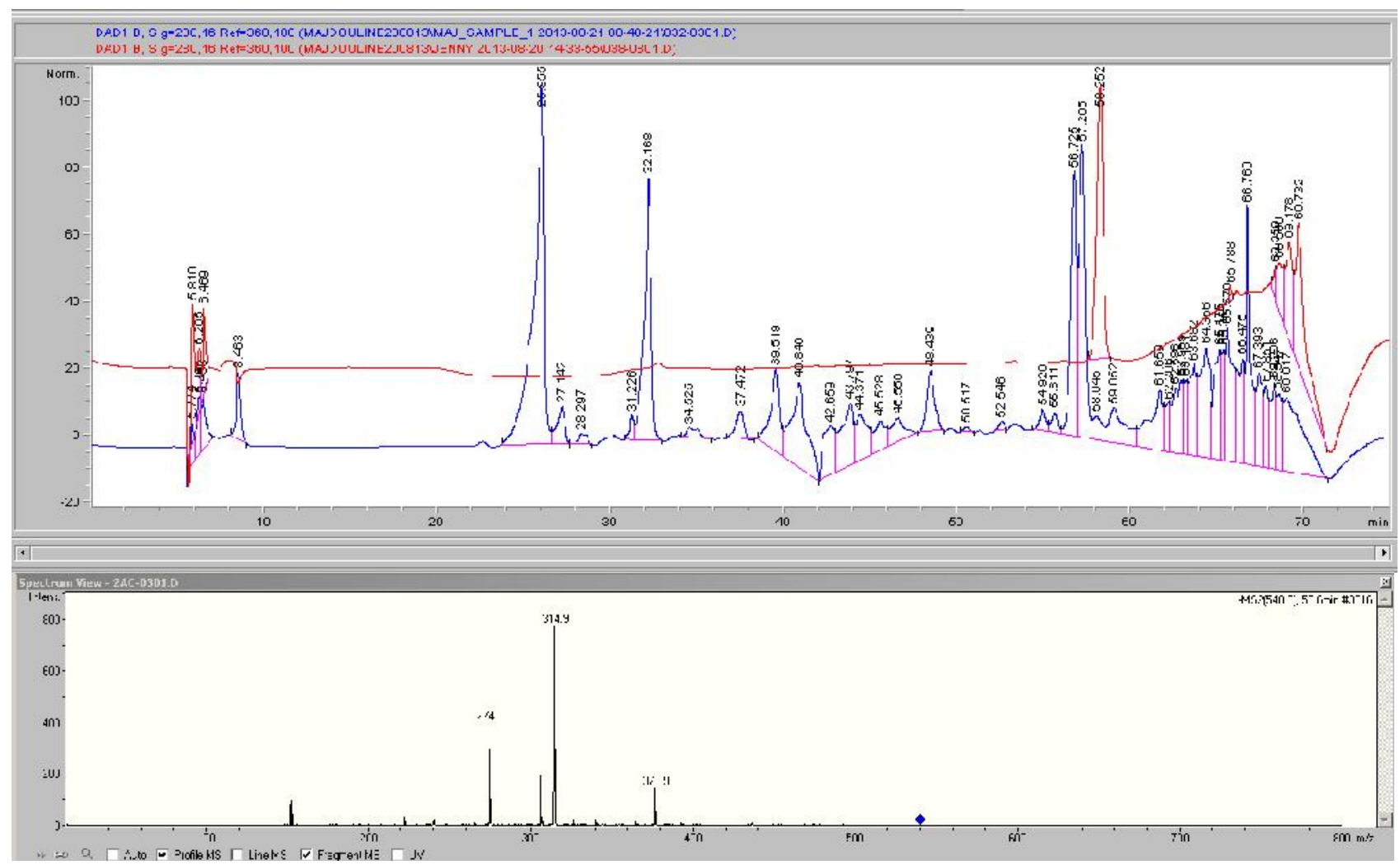

S2_P-coumaric (area $=500.266)$

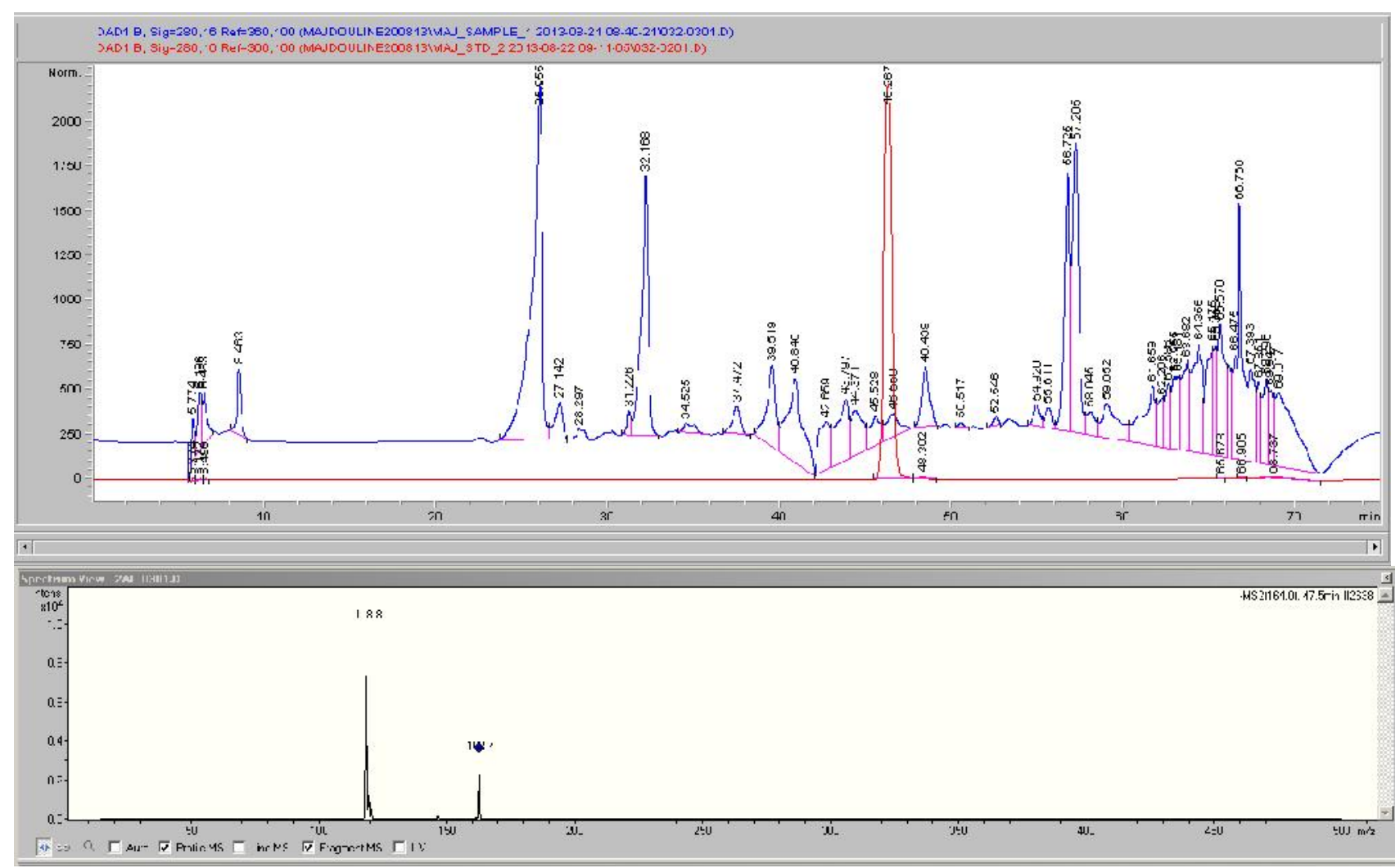

S3_hydroxytyrosol (area=15222.8) 


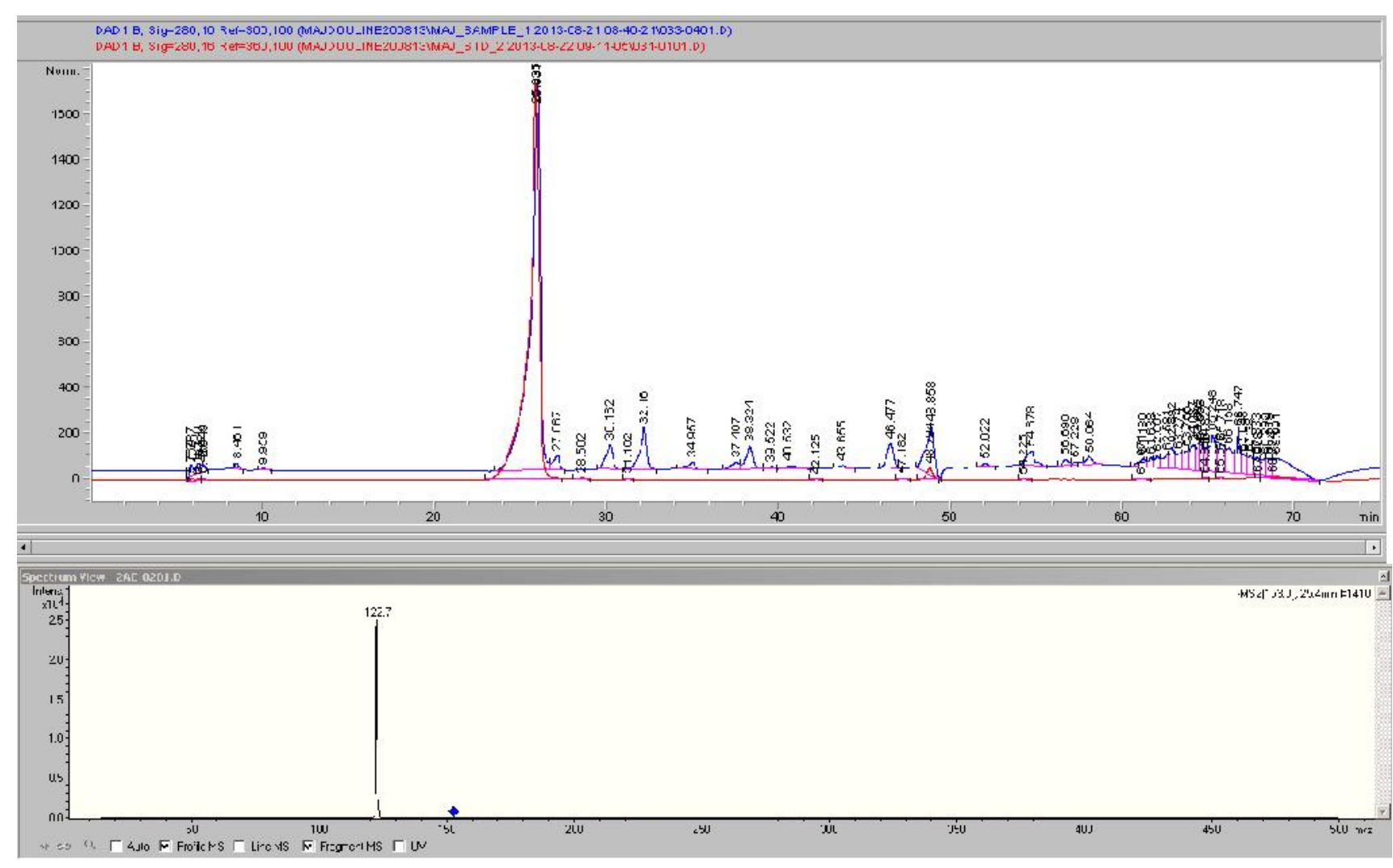

S3_Tyrosol $($ area $=1194.17)$

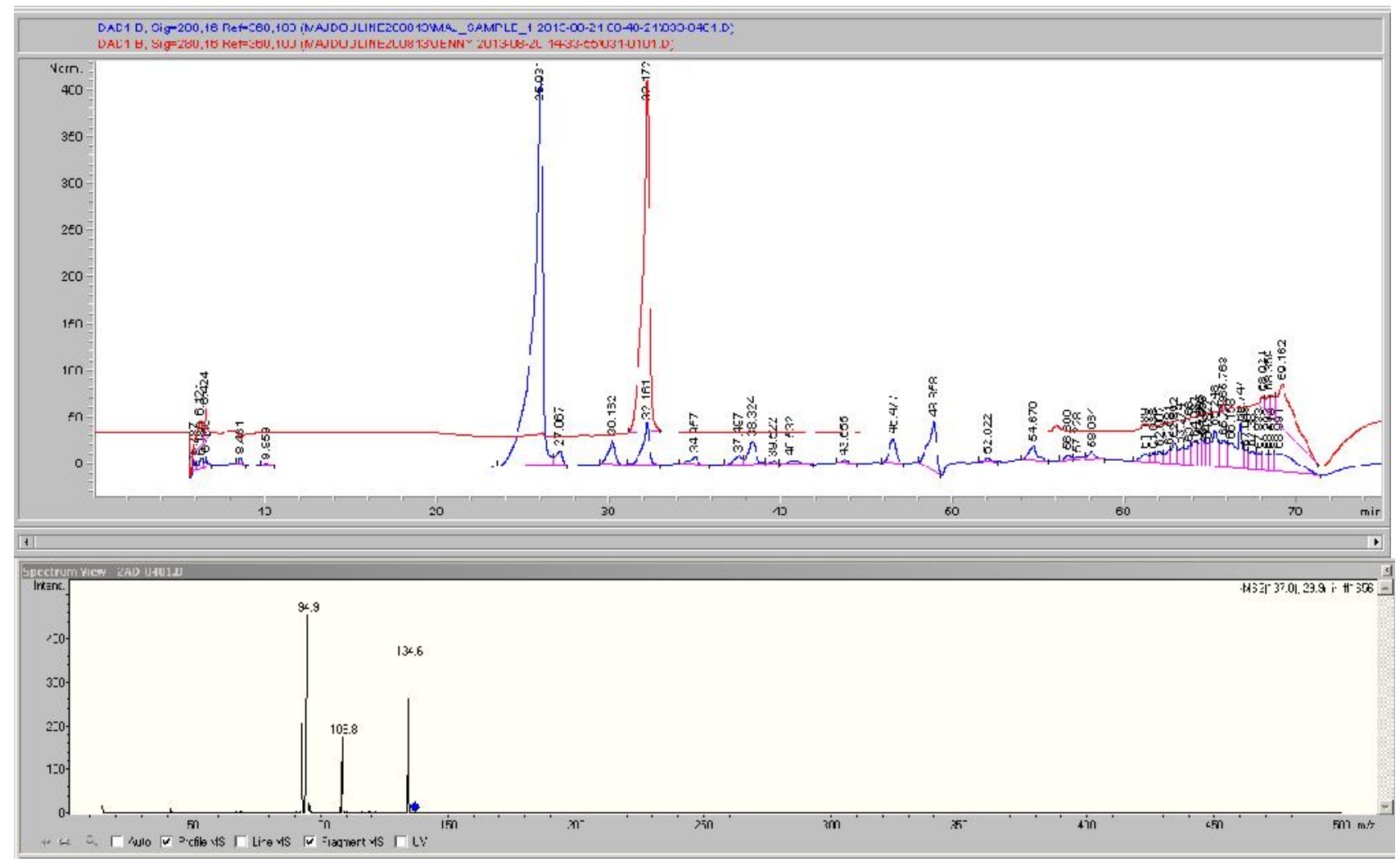


S3_Ferrulic acid (area $=1855.89,131.663$ )

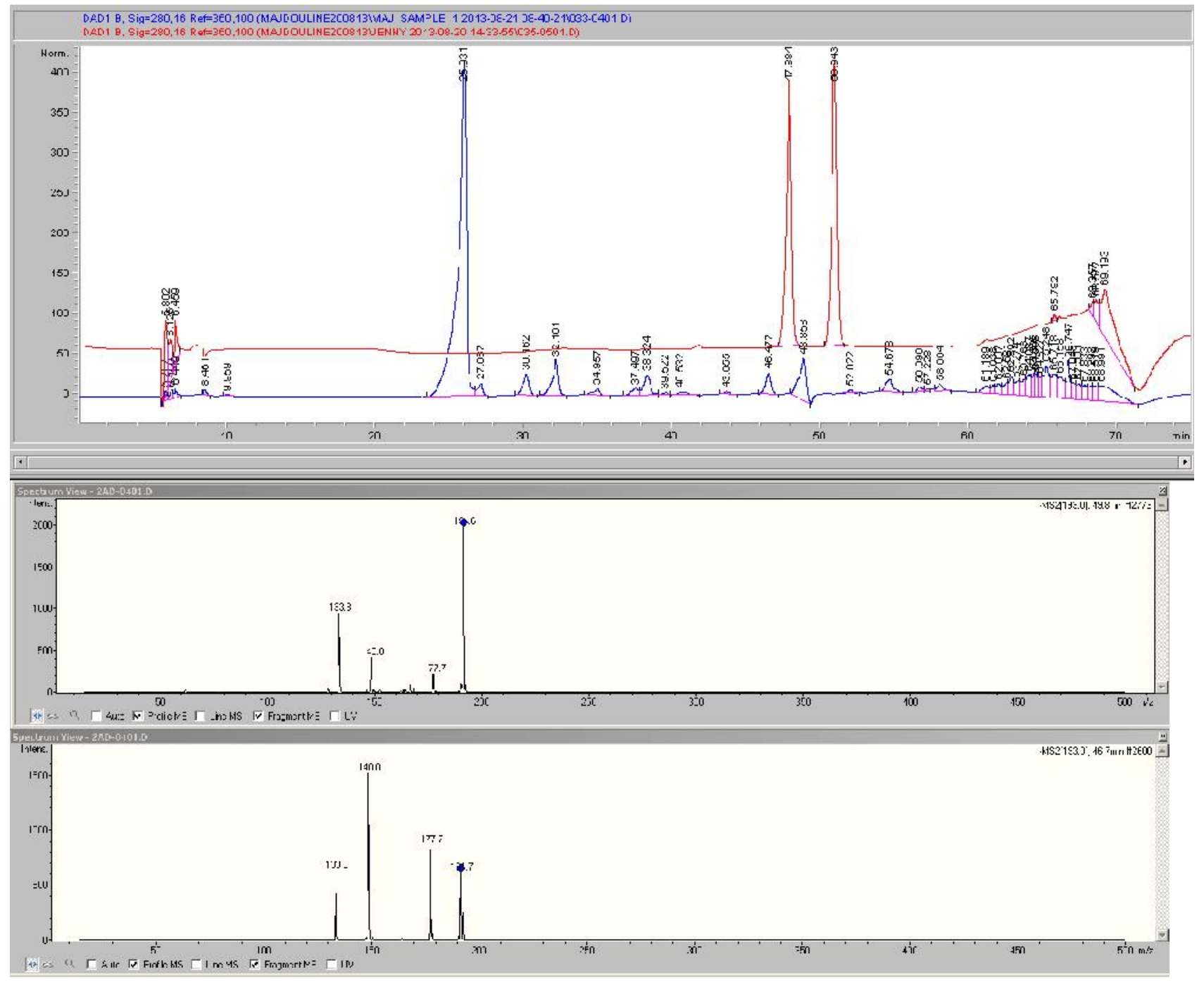

S3_Oleuropein (area=132.767) 


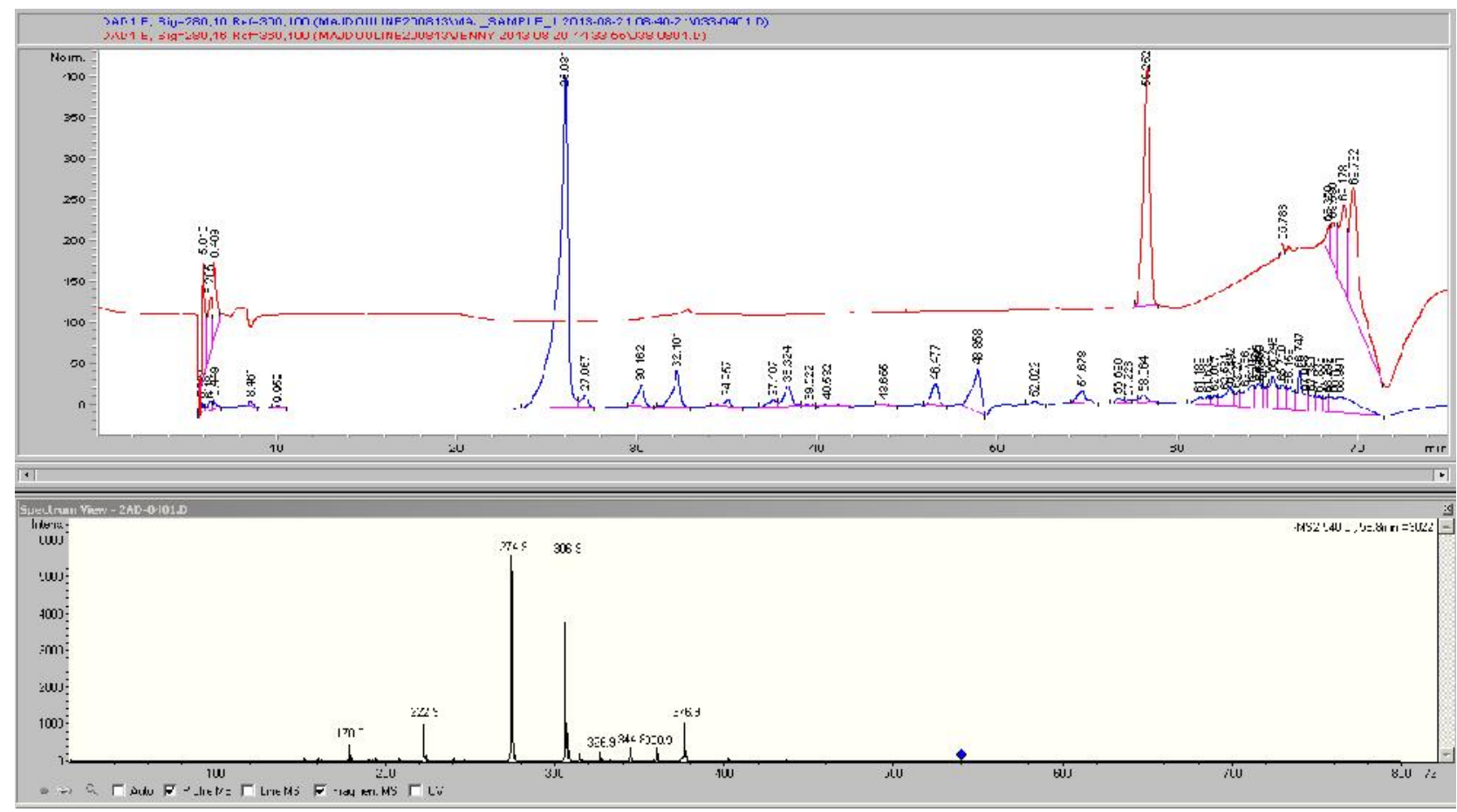

S3_P-coumaric acid (area $=613.024)$

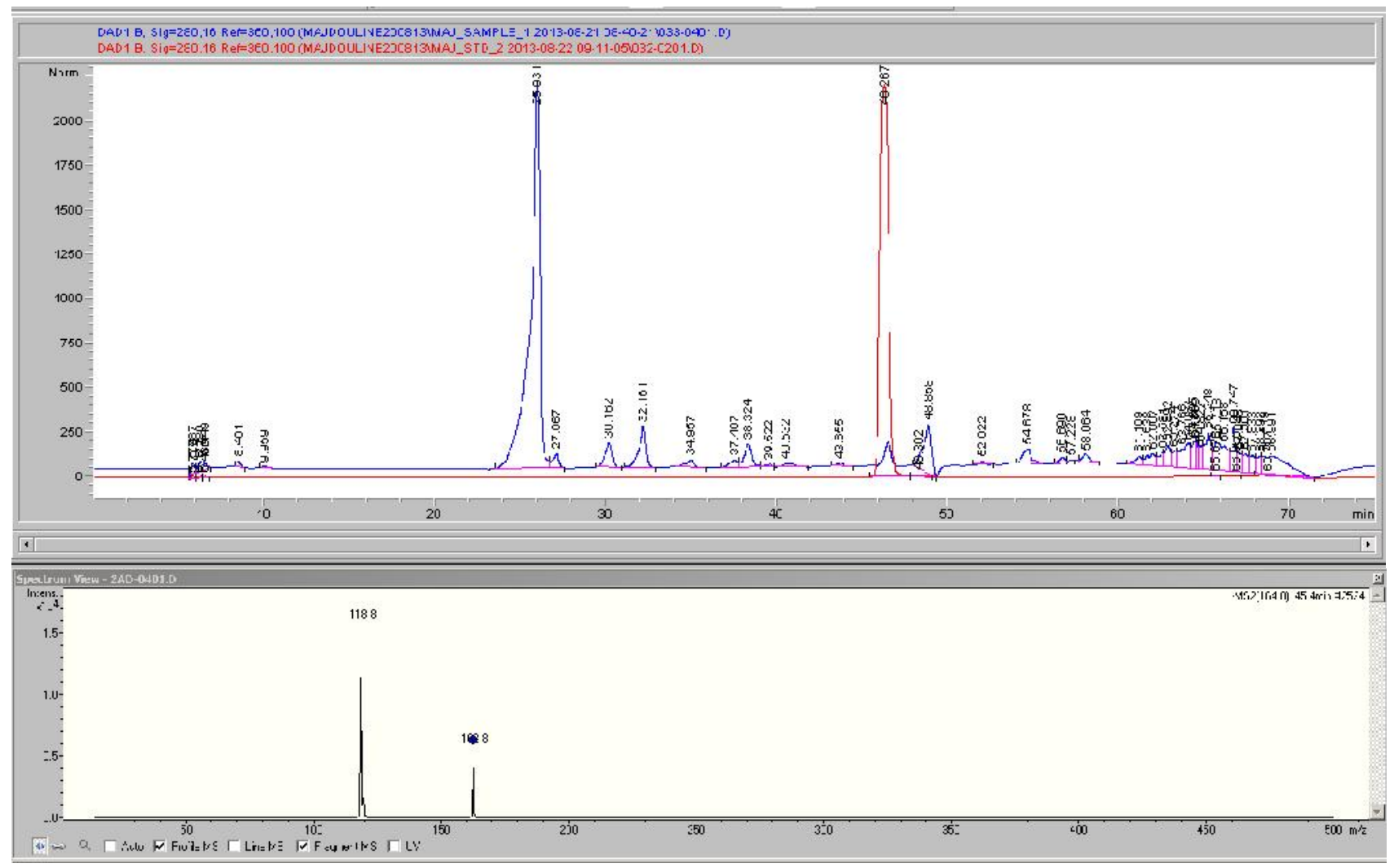

S4_Hydroxytyrosol (area=4471.02) 


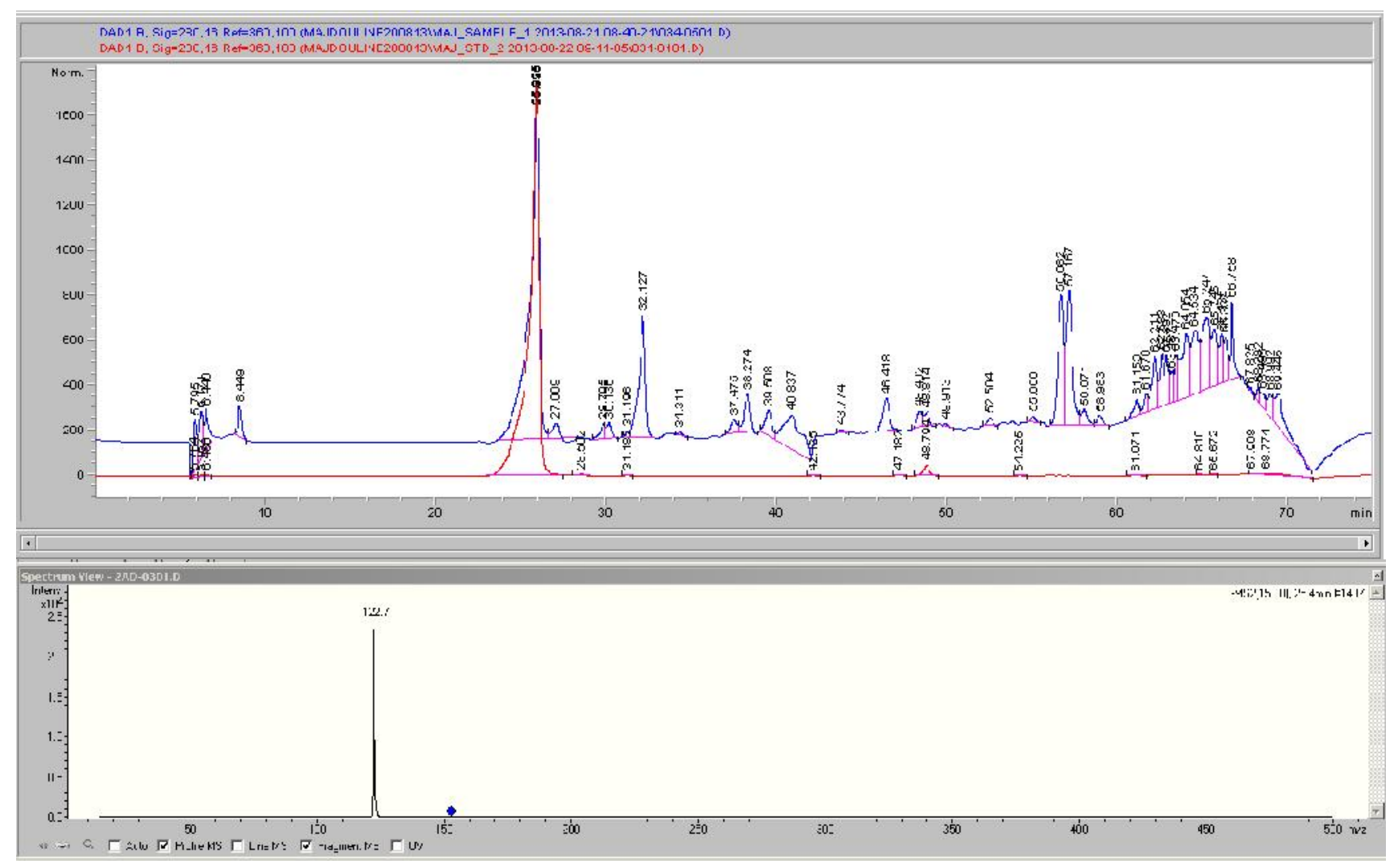

S4_Tyrosol (area=1069.74)

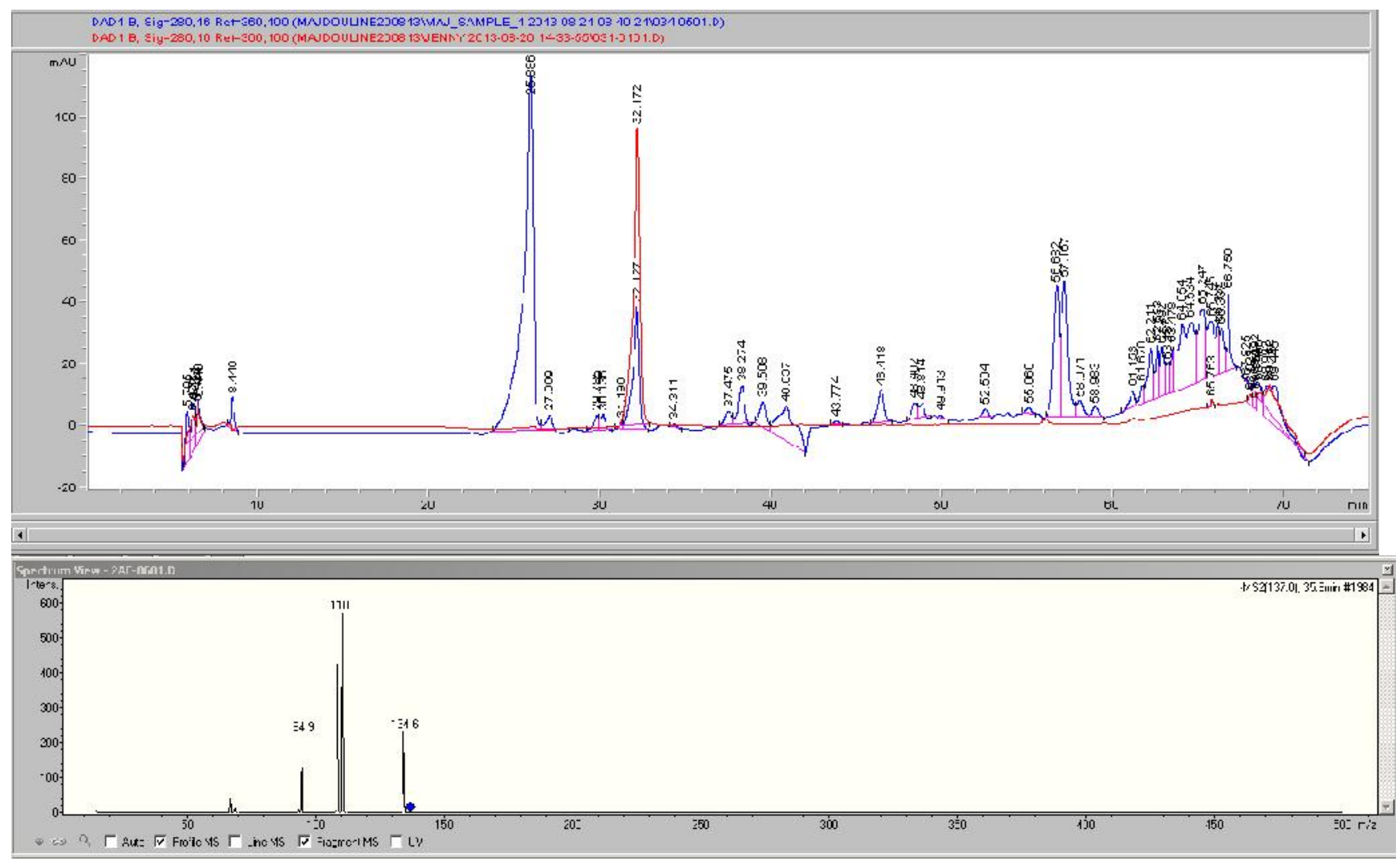


S4_P-coumaric acid (area=251.832)

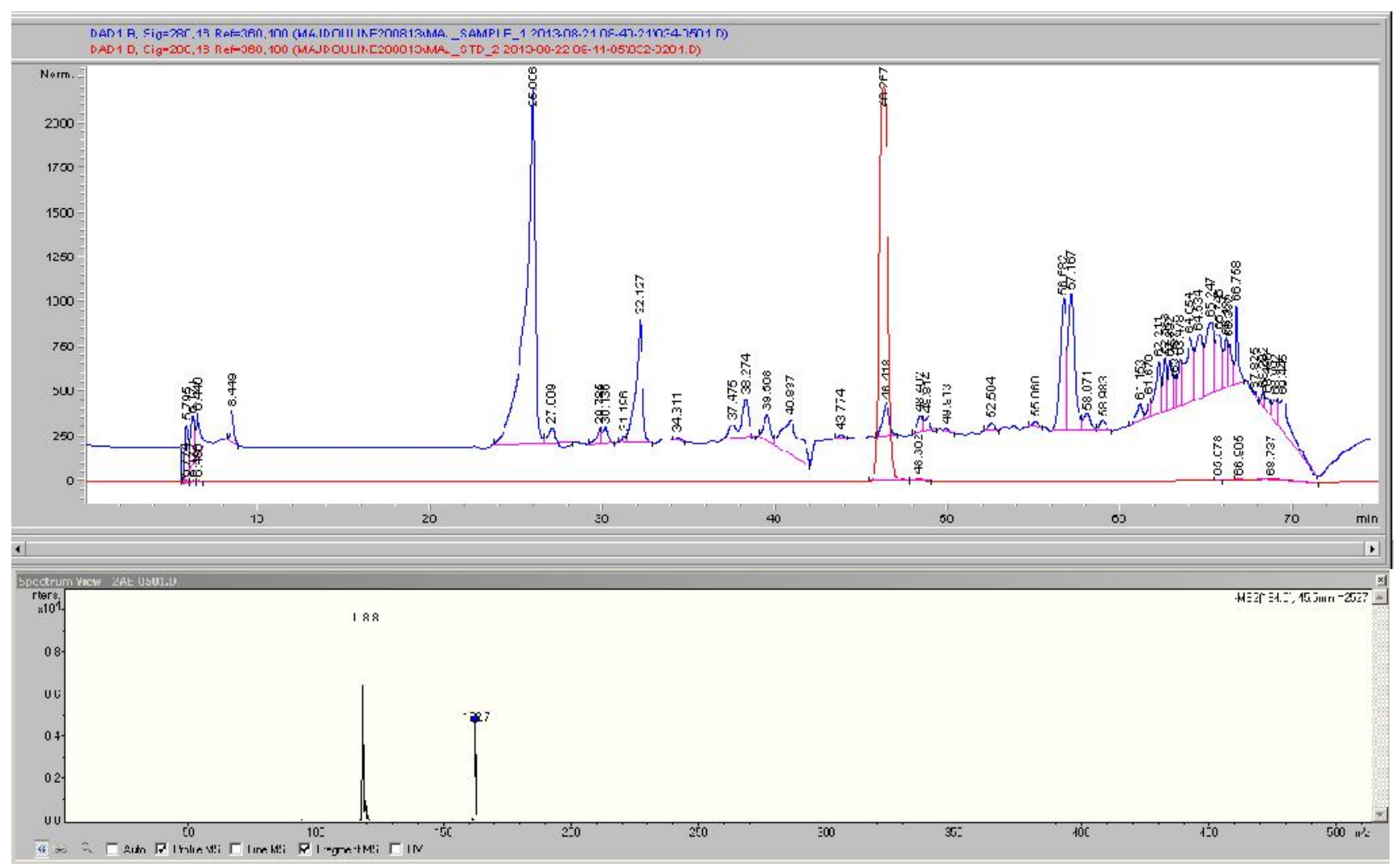

S4_Ferrulic acid (area=257.220, 36.74) 


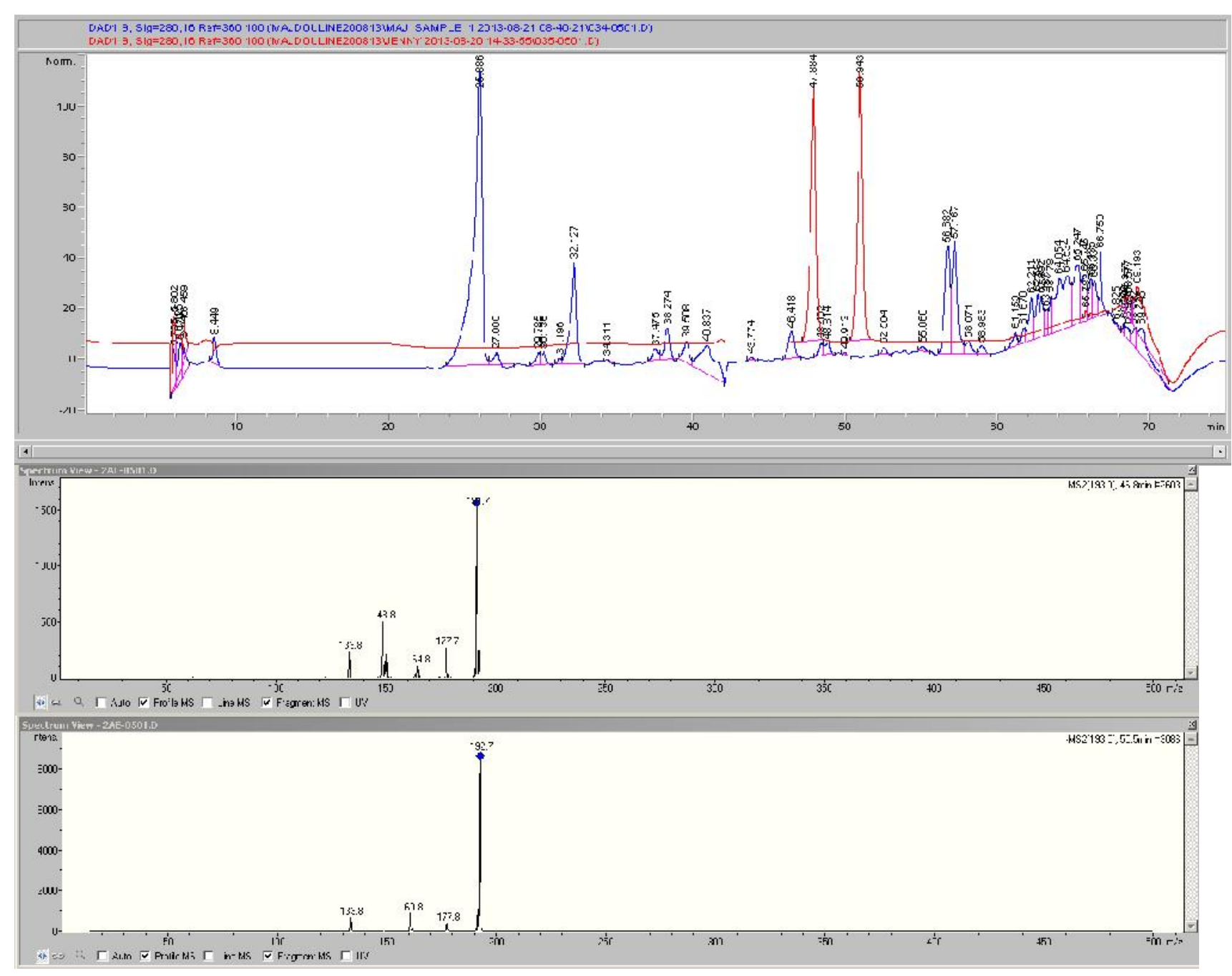

\section{S4_Oleuropein $($ area $=51.1121)$}

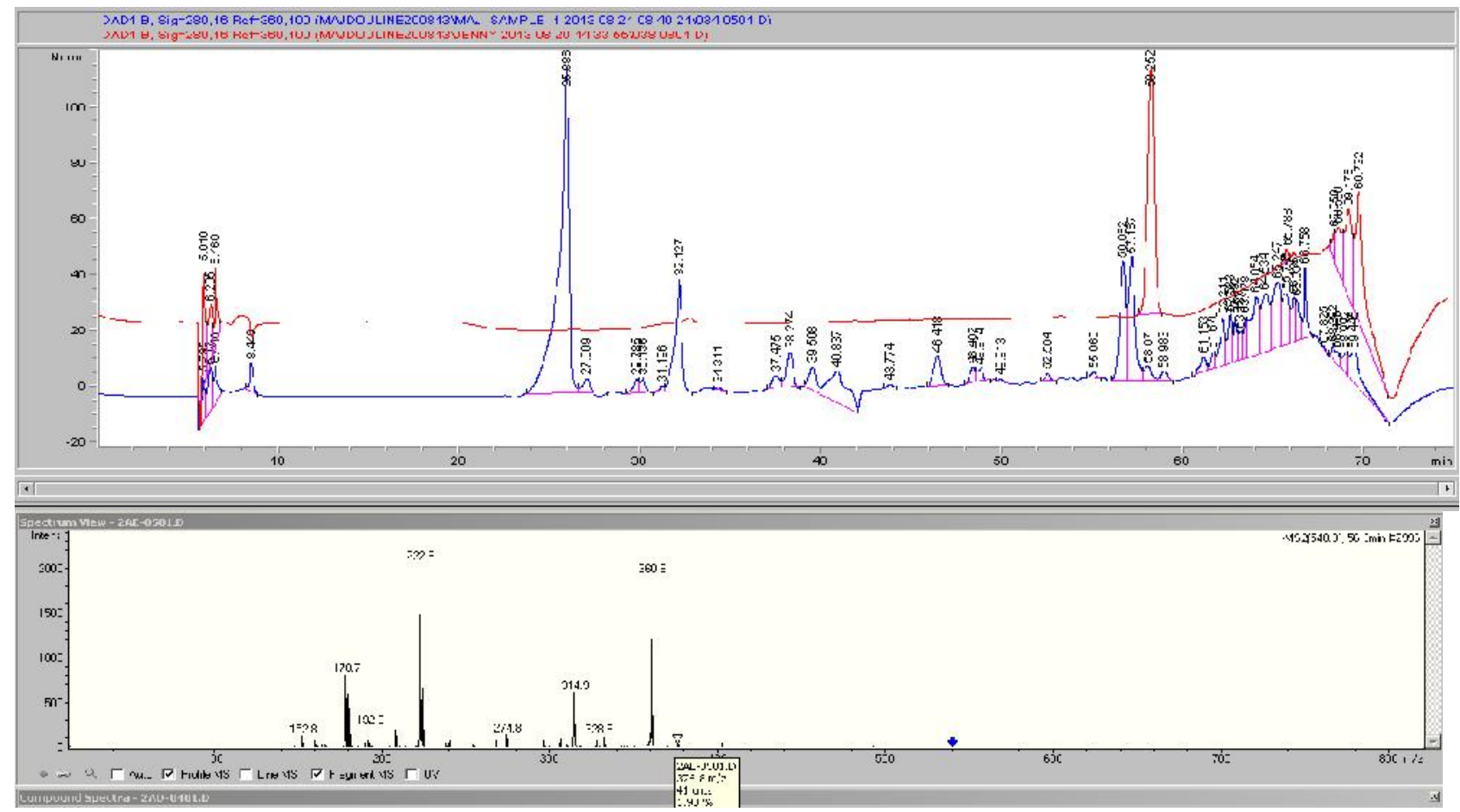


V_hydroxytyrosol (area $=74211.3$ )

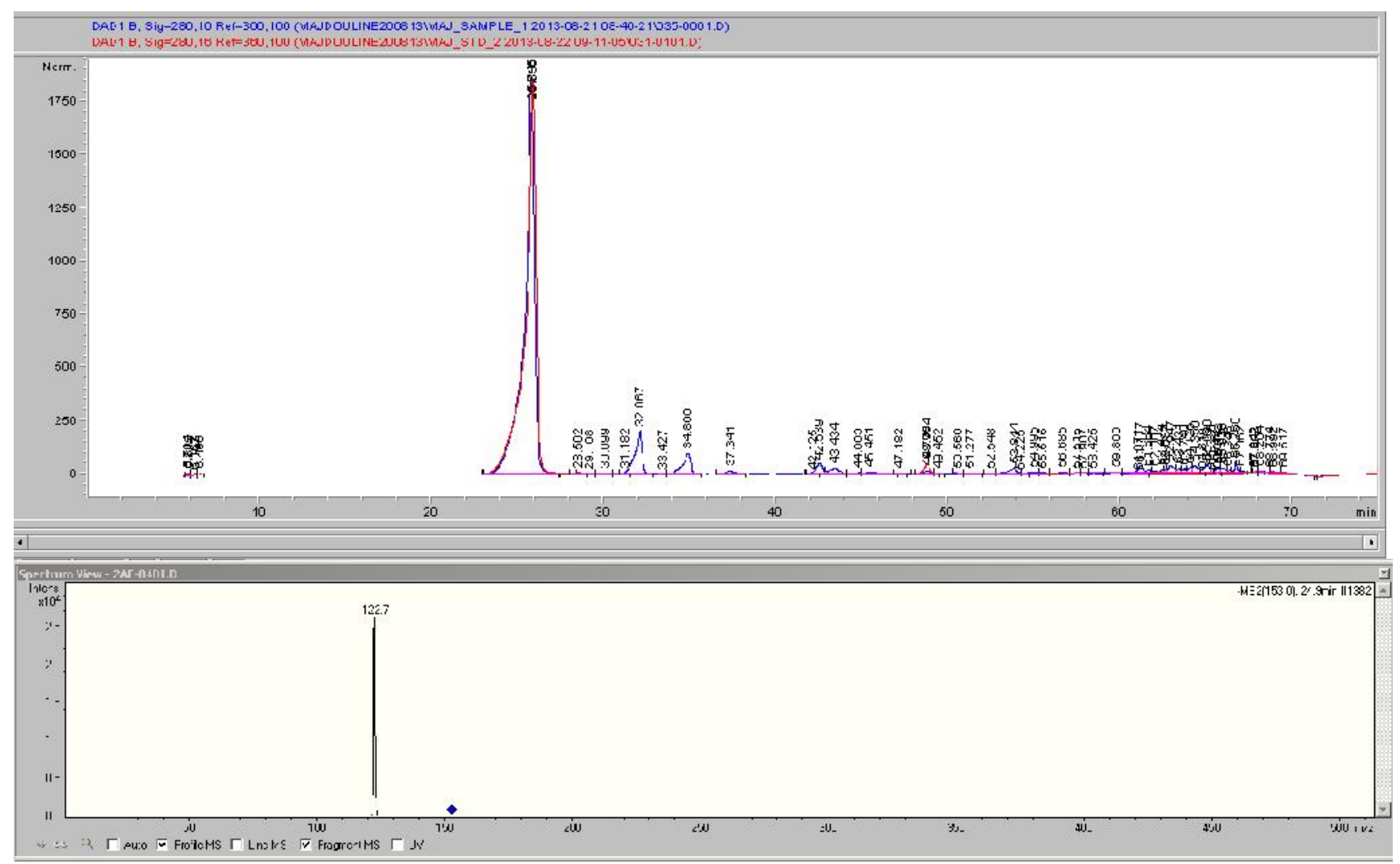

\section{V_Tyrosol (area $=5939.05)$}

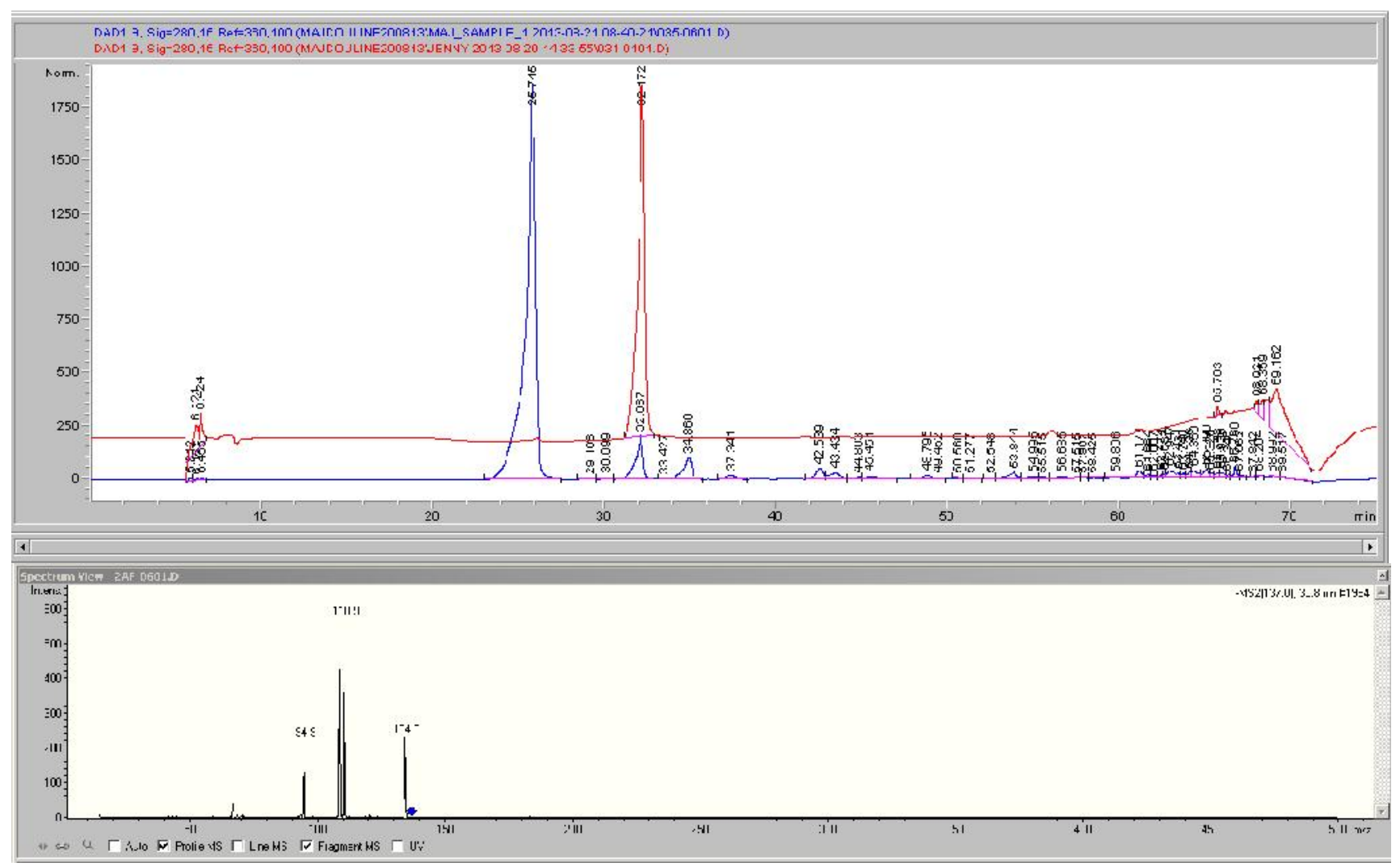


V_oleuropein (area $=23.75)$

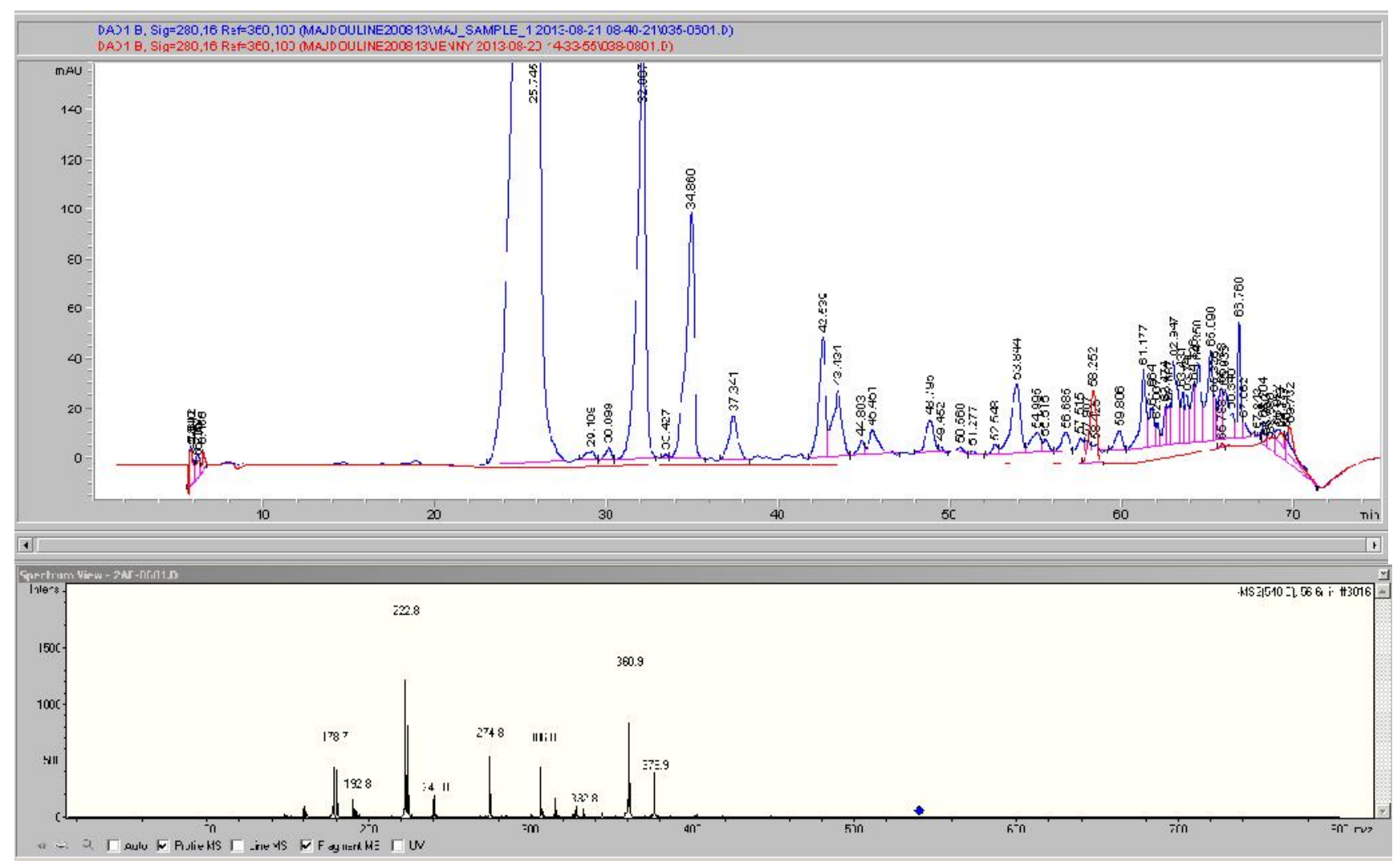

T_Hydroxytyrosol (area=43125.4)

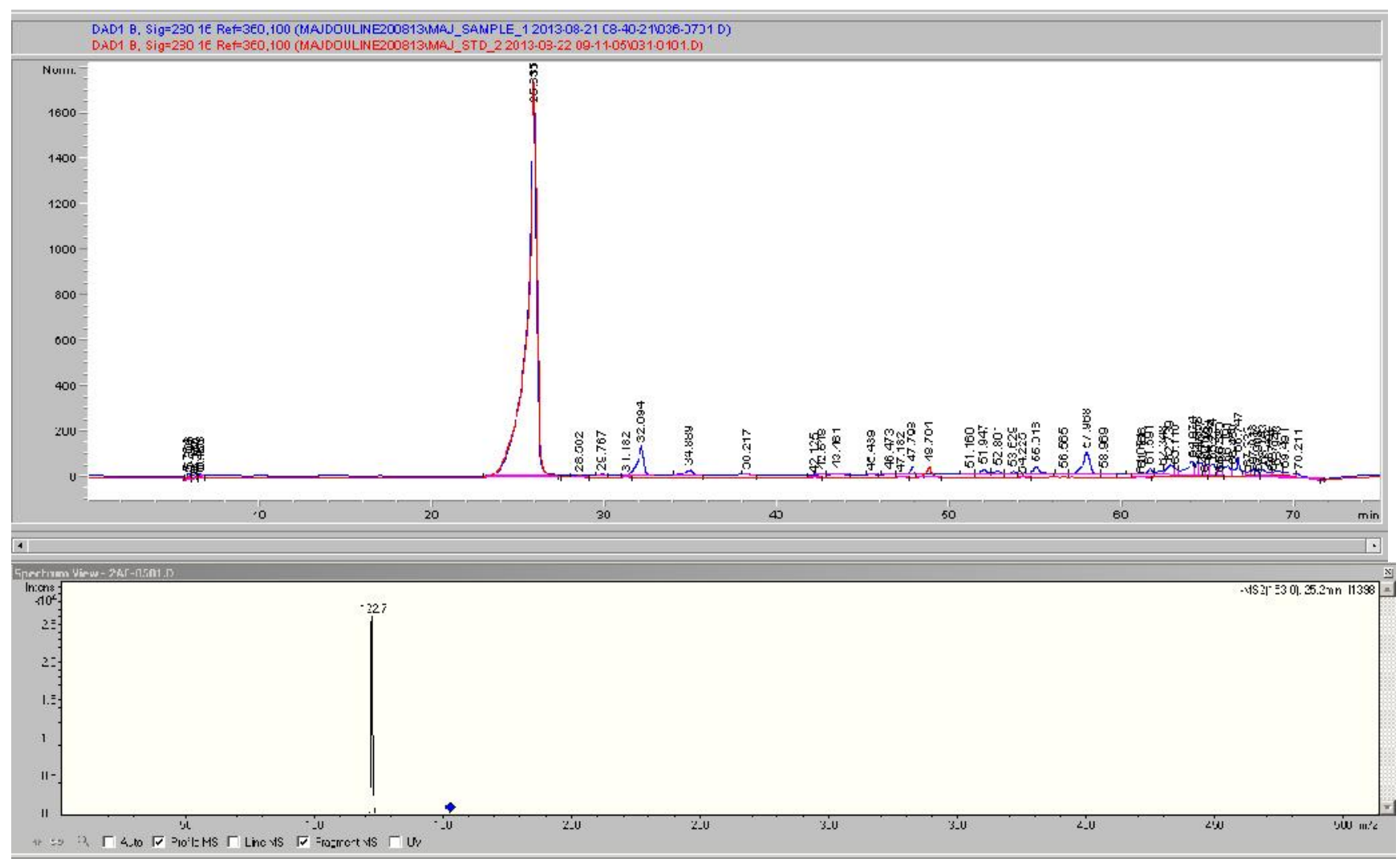




\section{T_Tyrosol (area $=2208.98)$}

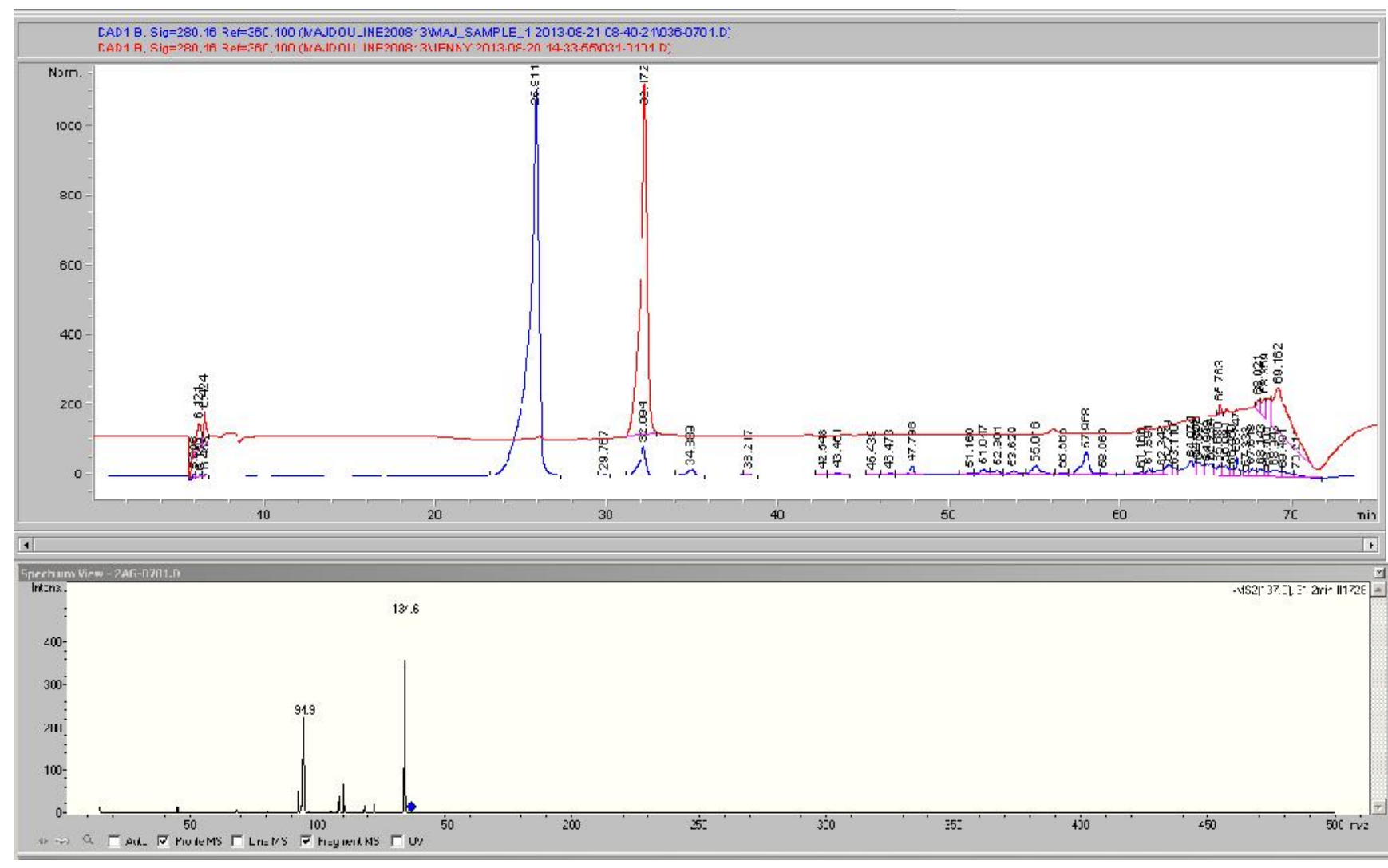

\section{T_Oleuropein (area=1750.8)}

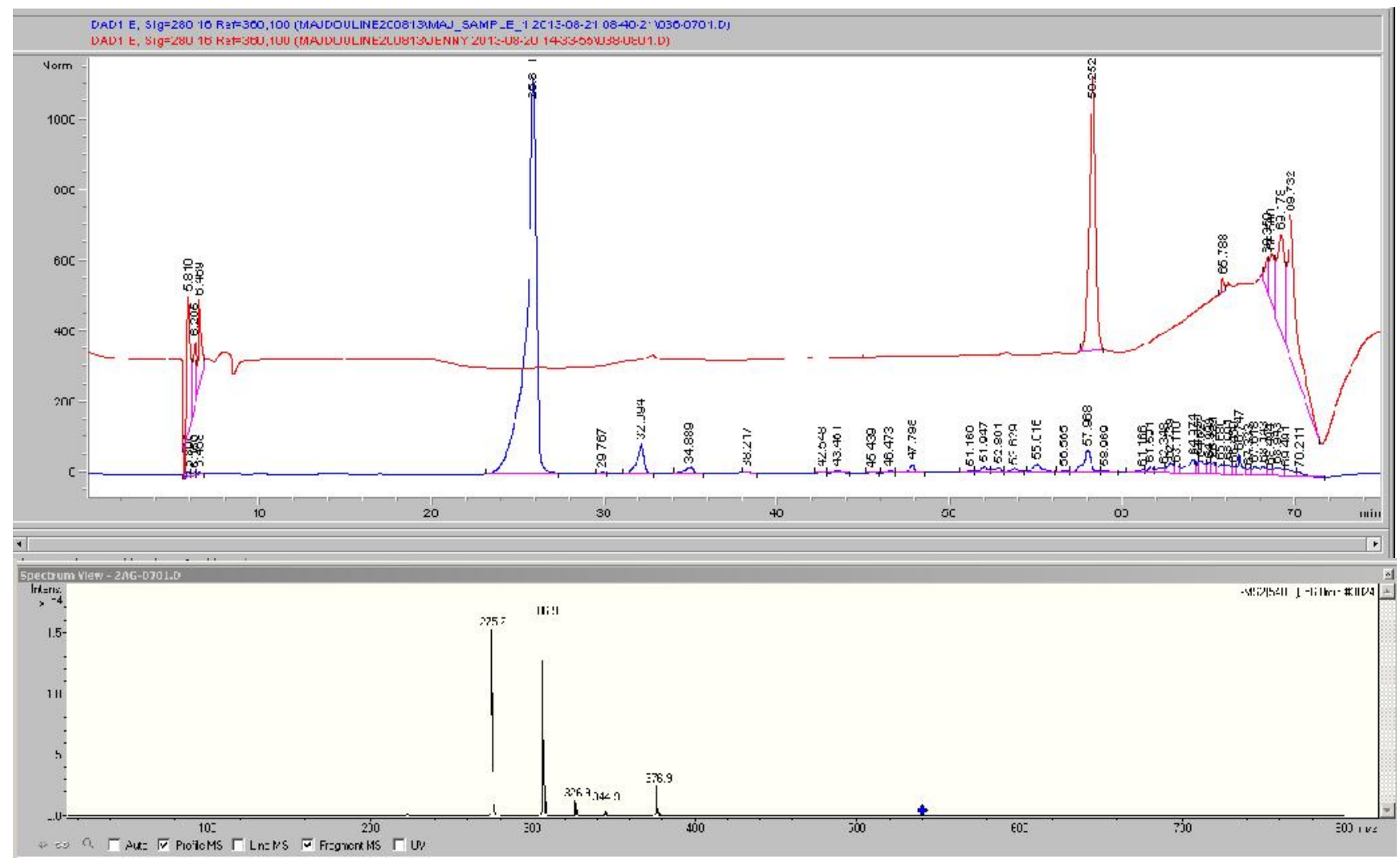


T_P-coumaric acid (area $=282.313$ )

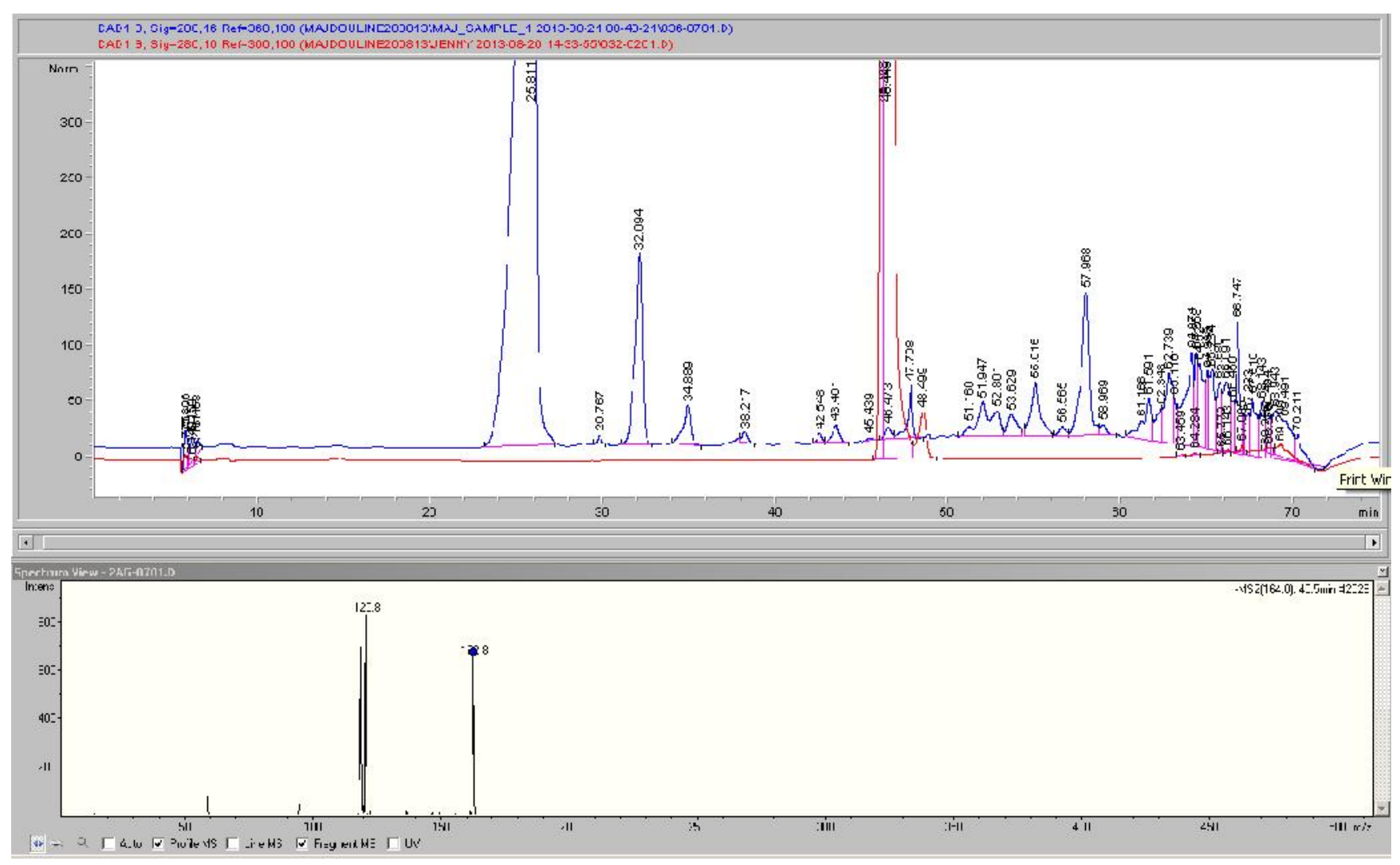

N_Hydroxytyrosol (area=9663.47) 


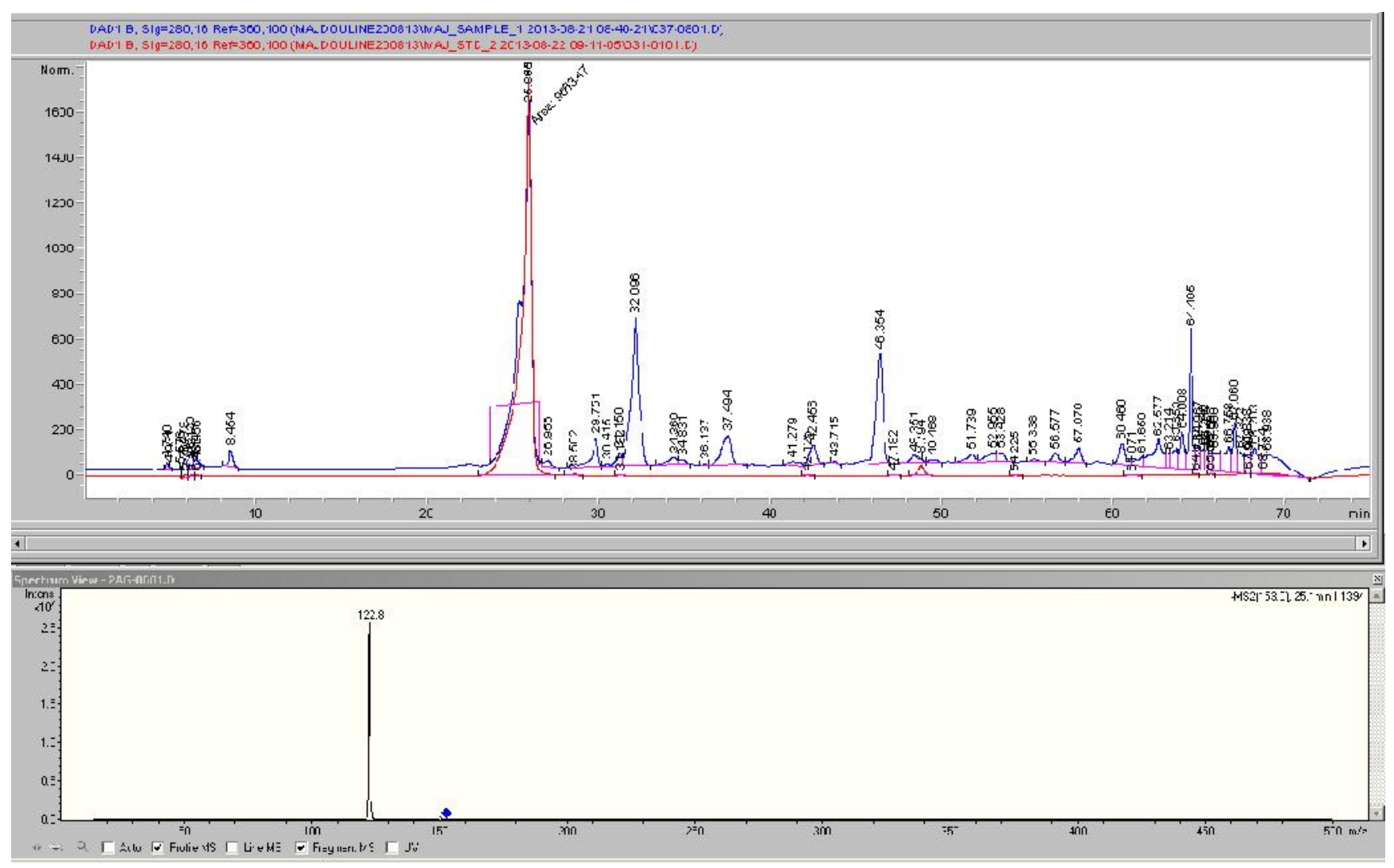

\section{N_Tyrosol (area $=4410.57)$}

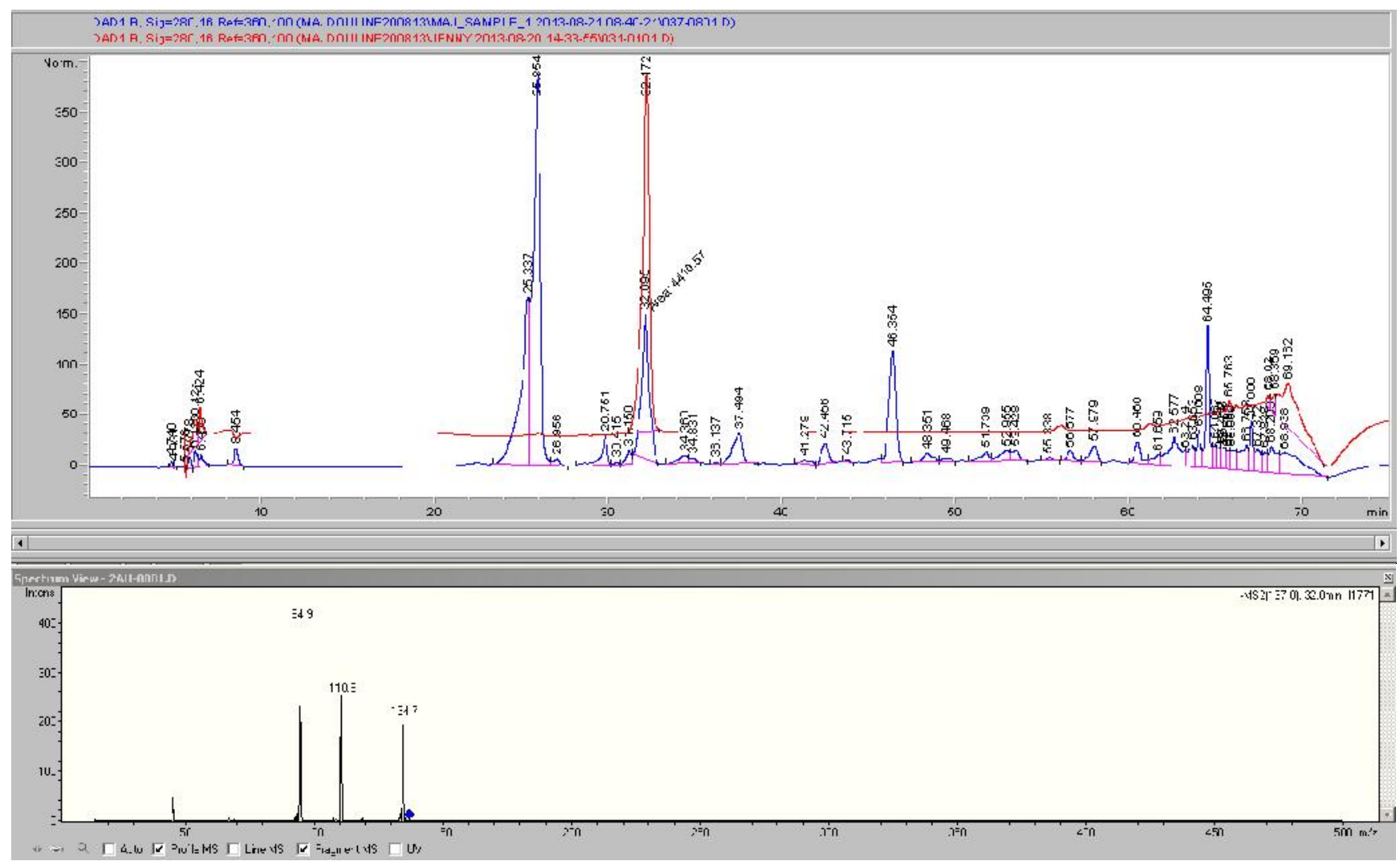




\section{N_Oleuropein (area=388.036)}

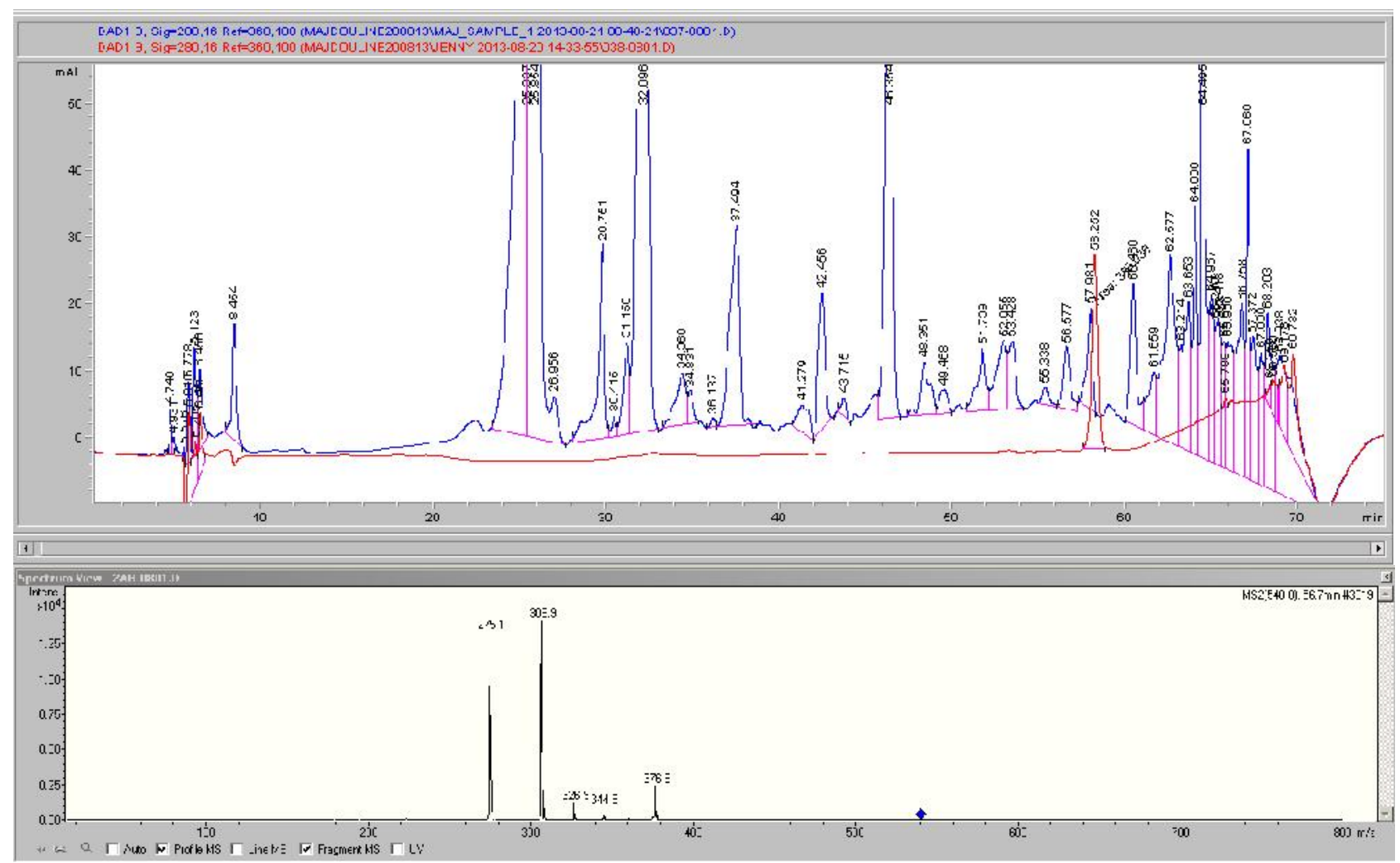

N_ferrulic acid (area $=14.04,35.28)$ 


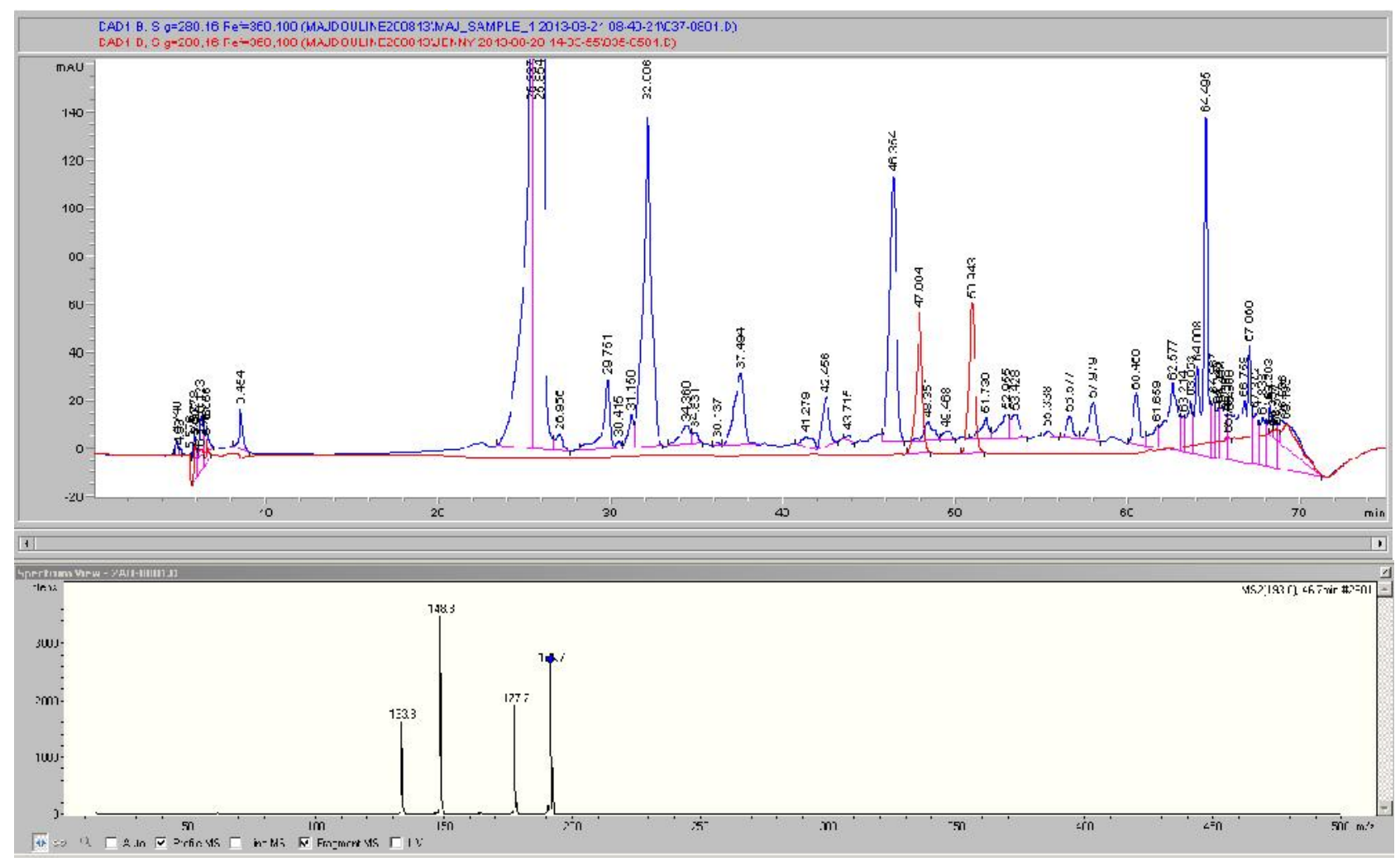

\section{N_P-coumaric acid (area $=222.965)$}

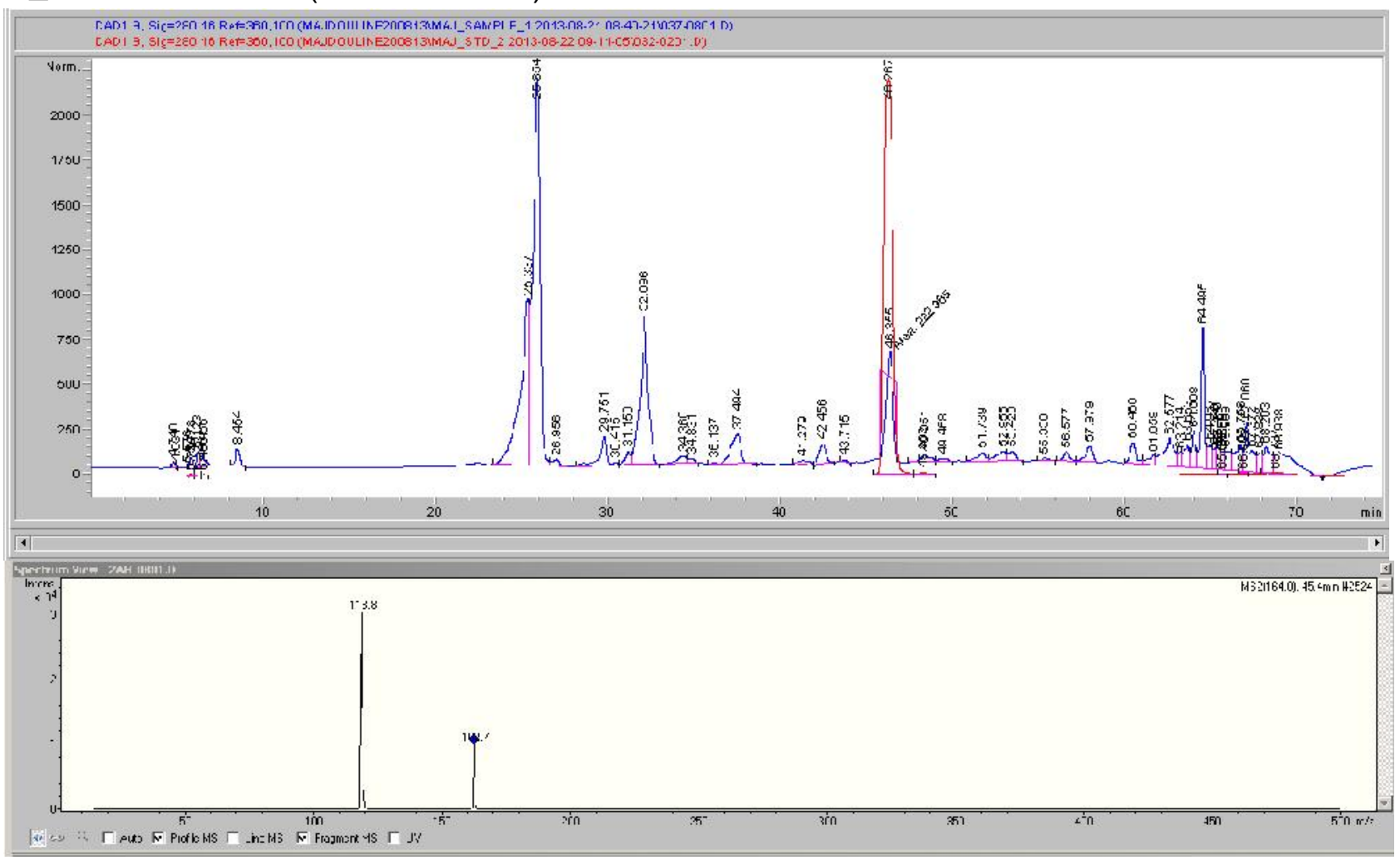




\section{S1F1_Tyrosol $($ area $=30.0784)$}

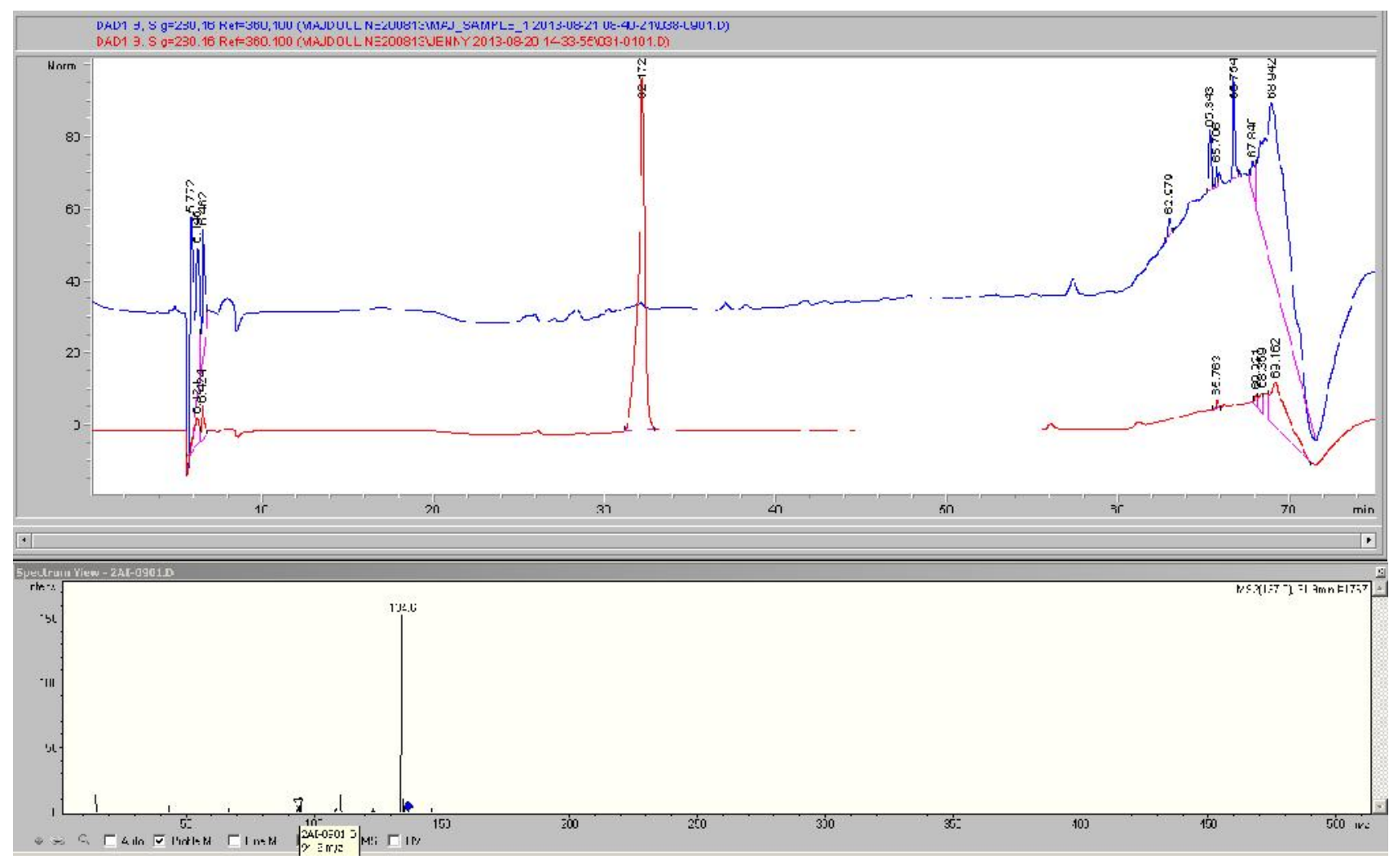

\section{S1F6_Hydroxytyrosol (area=1075.7)}

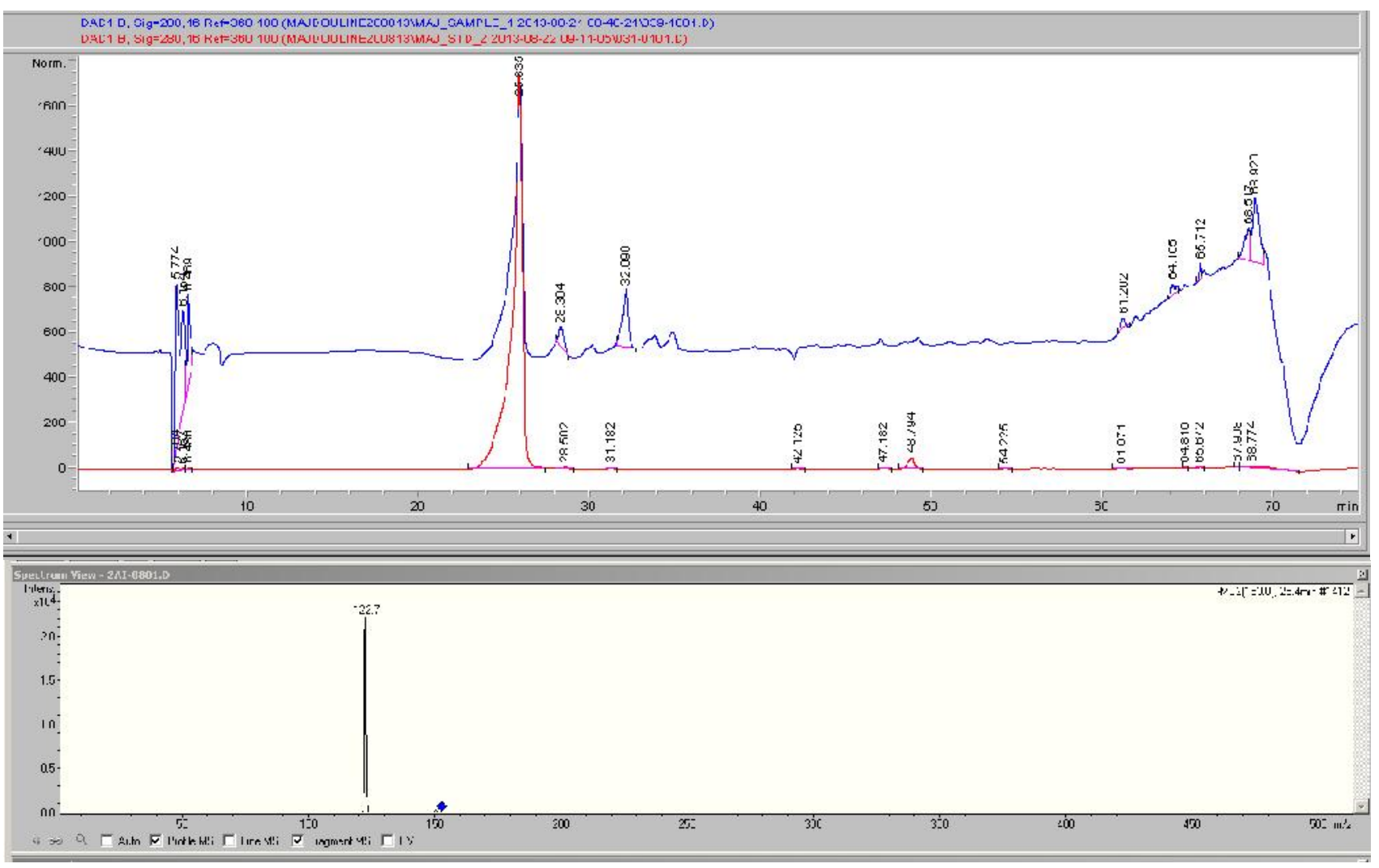


S1F6_Oleuropein (area=13.74)

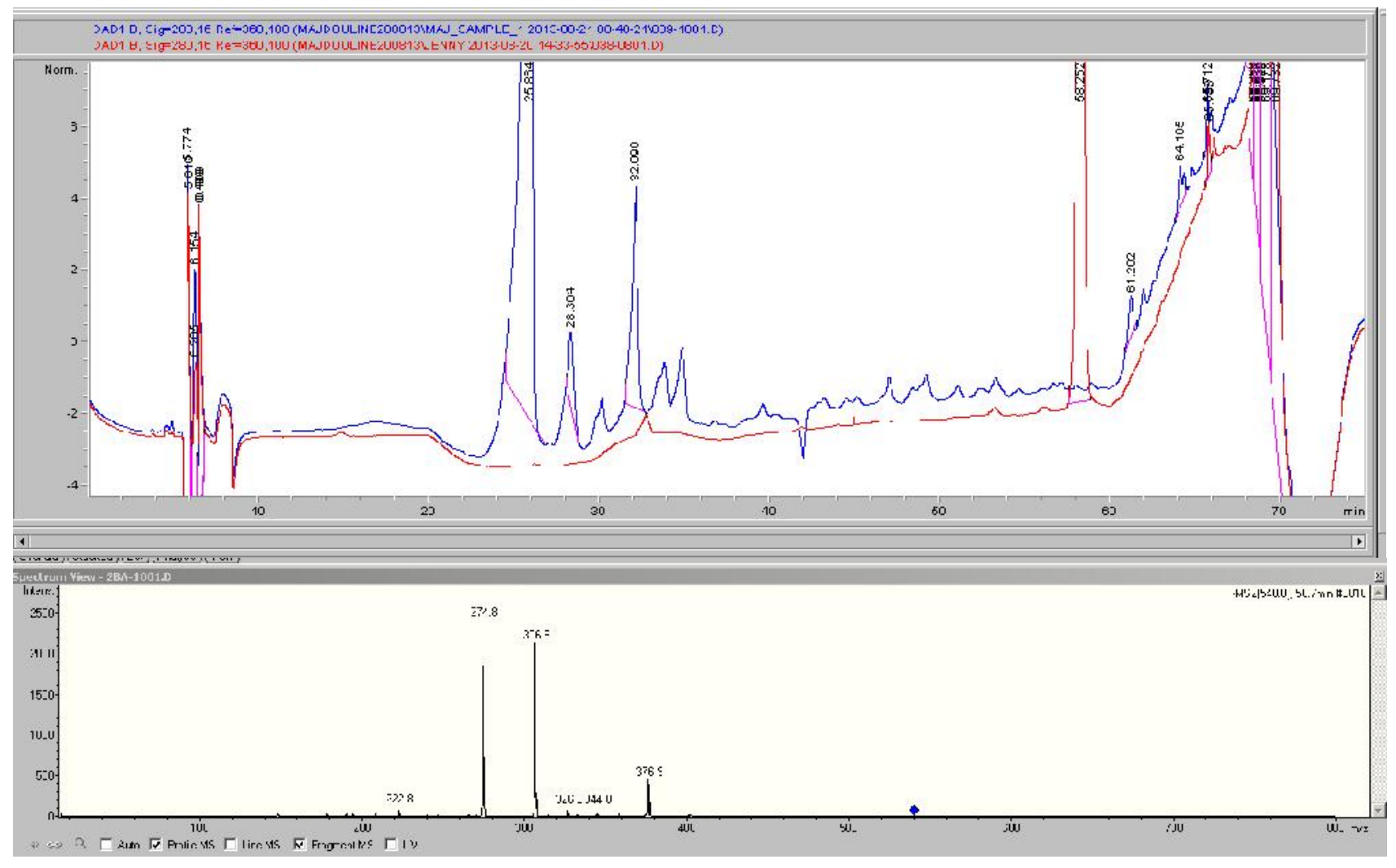

\section{S1F7_Hydroxytyrosol (area=2085.74)}

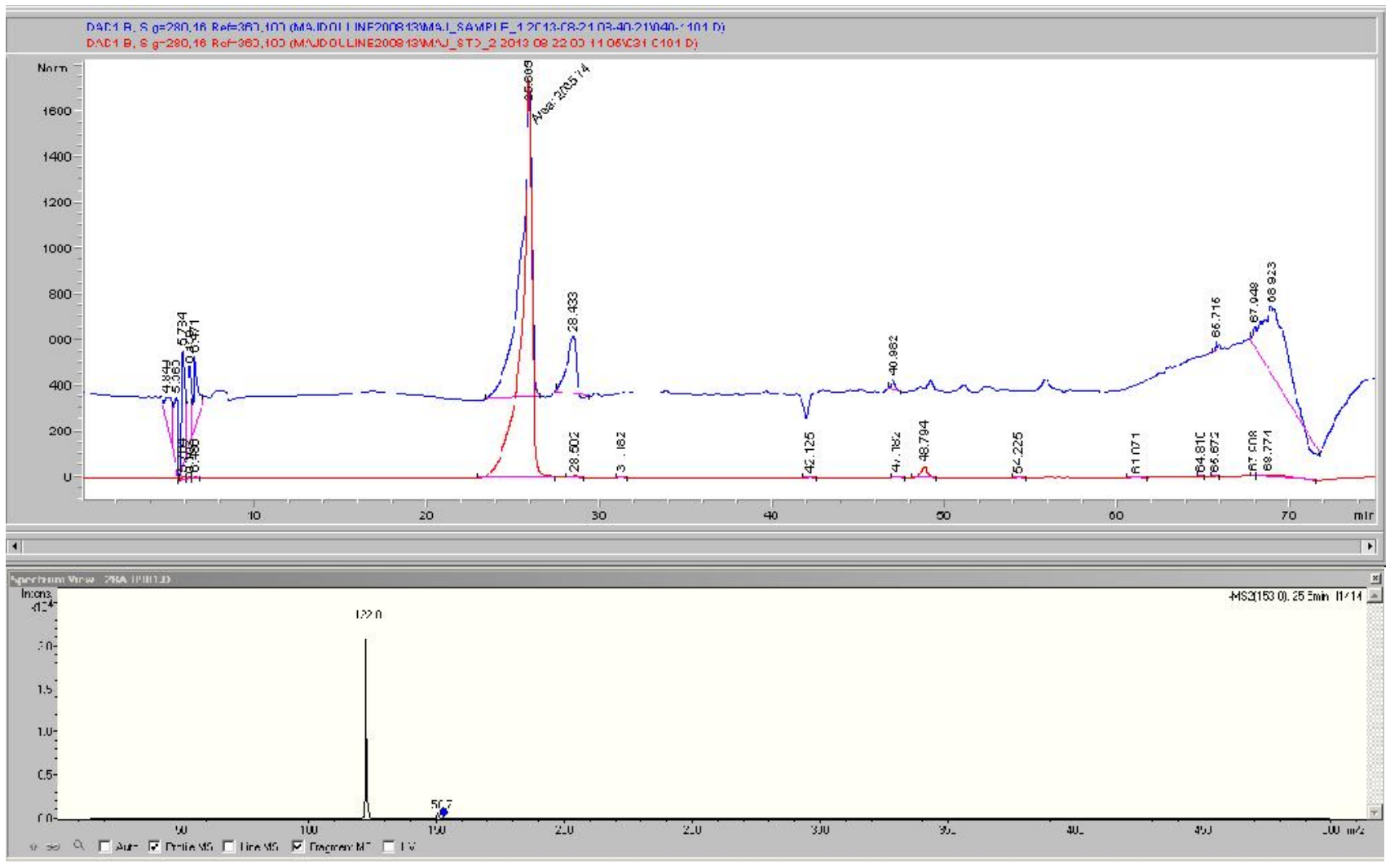


S1F8 $=$ no confirmed compound

S1F9_oleuropein (area=54.1245)

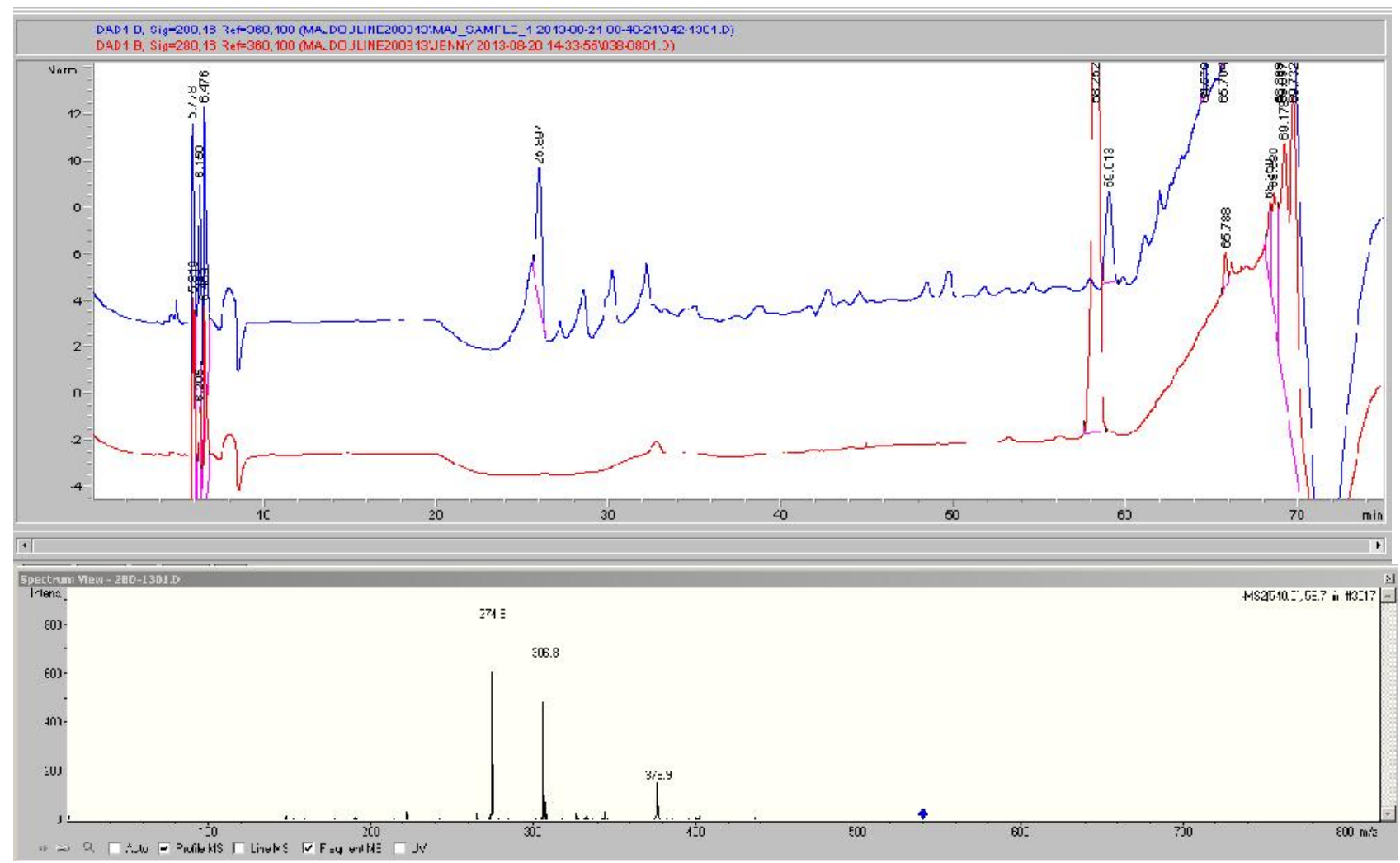


S2F2_Oleuropein (area=67.5804)

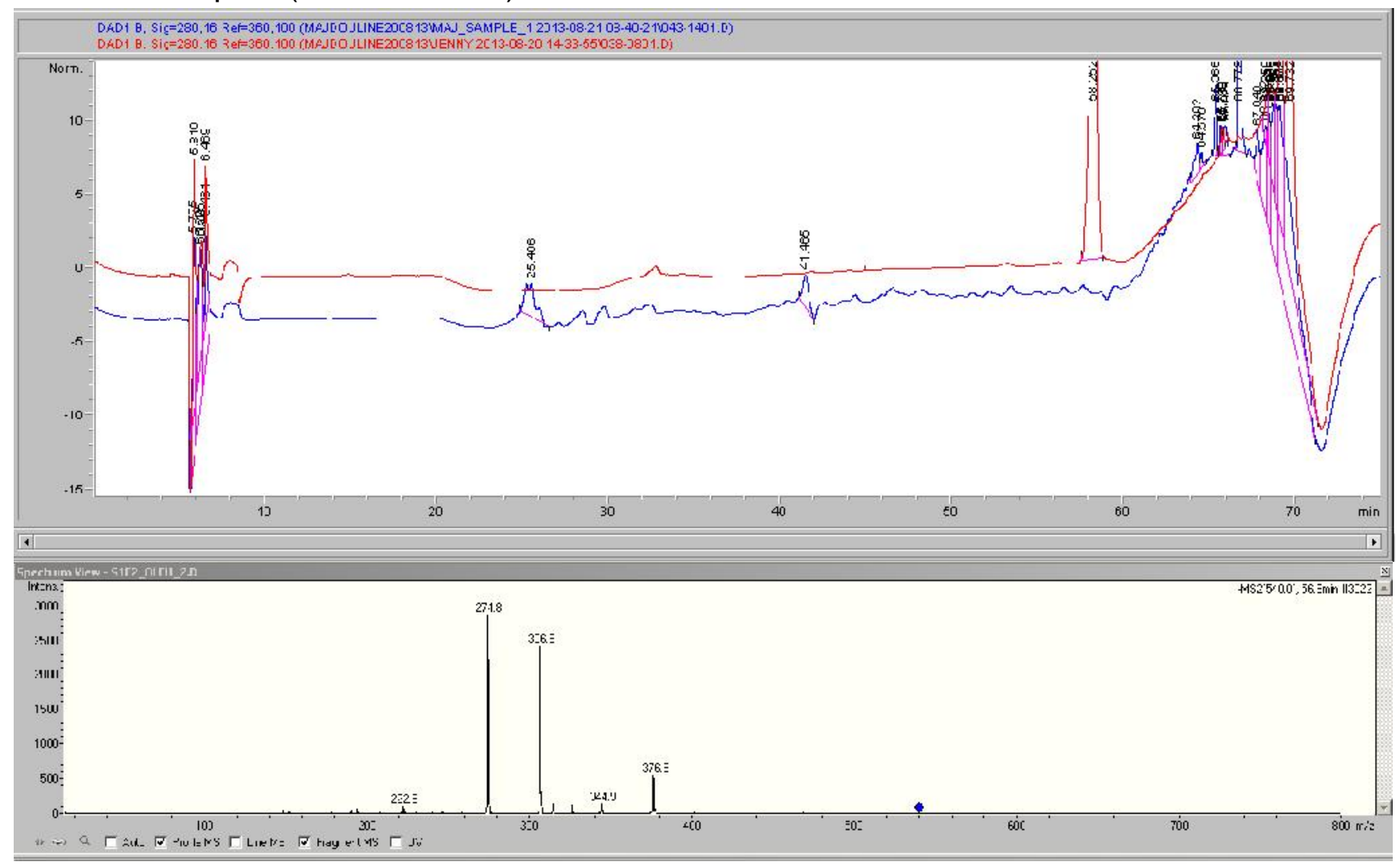

\section{S2F4_tyrosol (area=39.4247)}

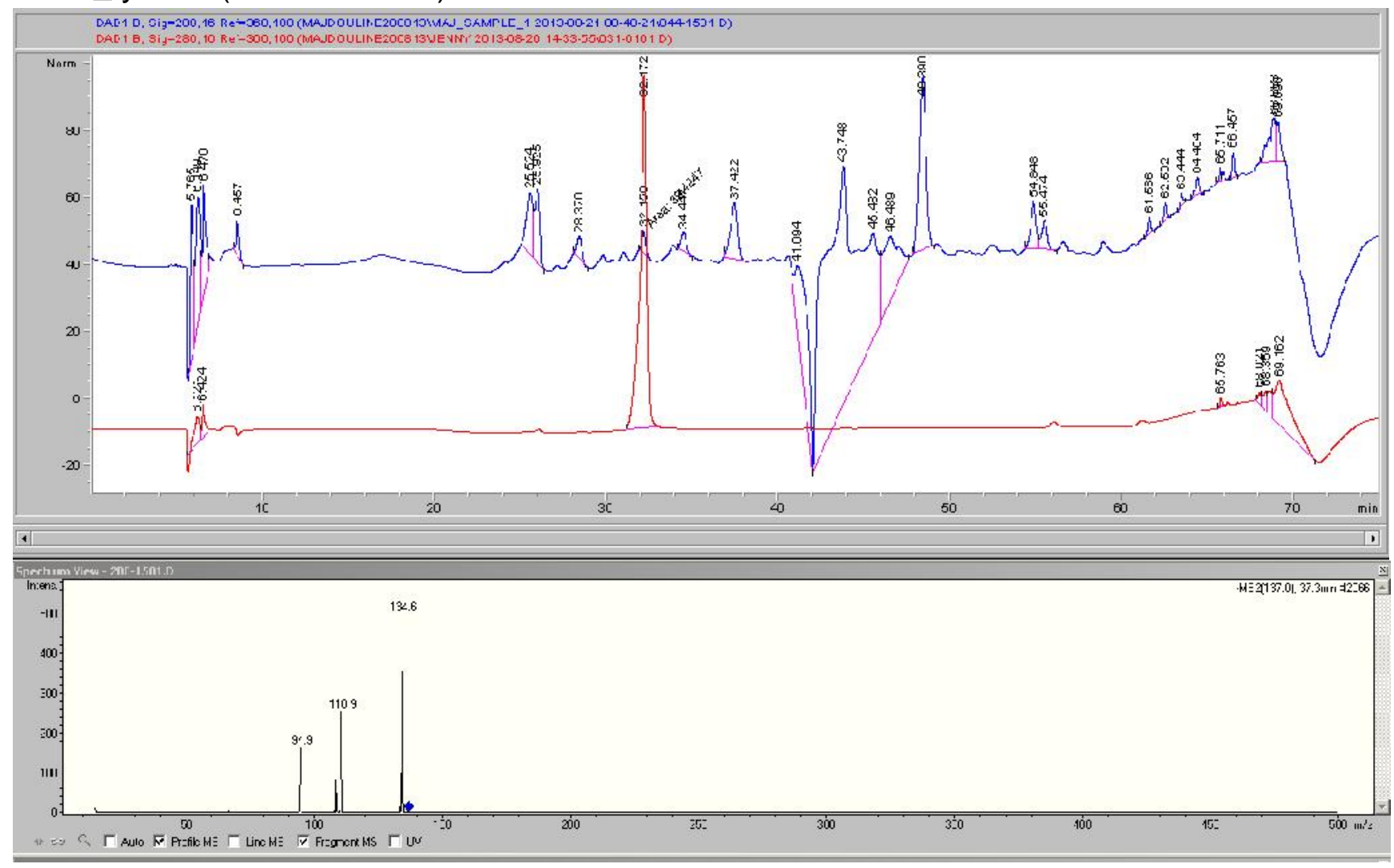


S2F4_Oleuropein (area=34.78)

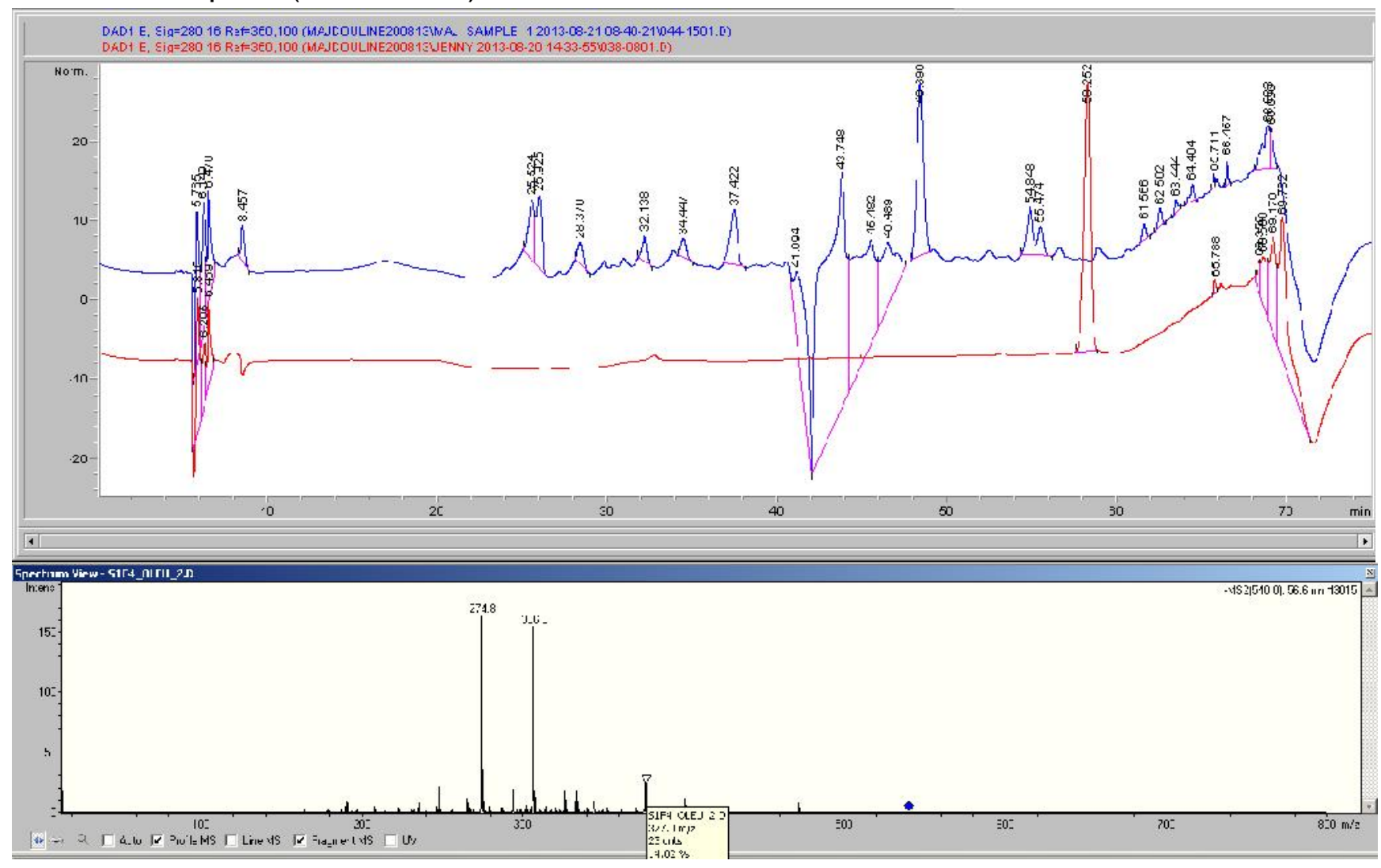

\section{S2F4_P-coumaric acid (area=45.24)}

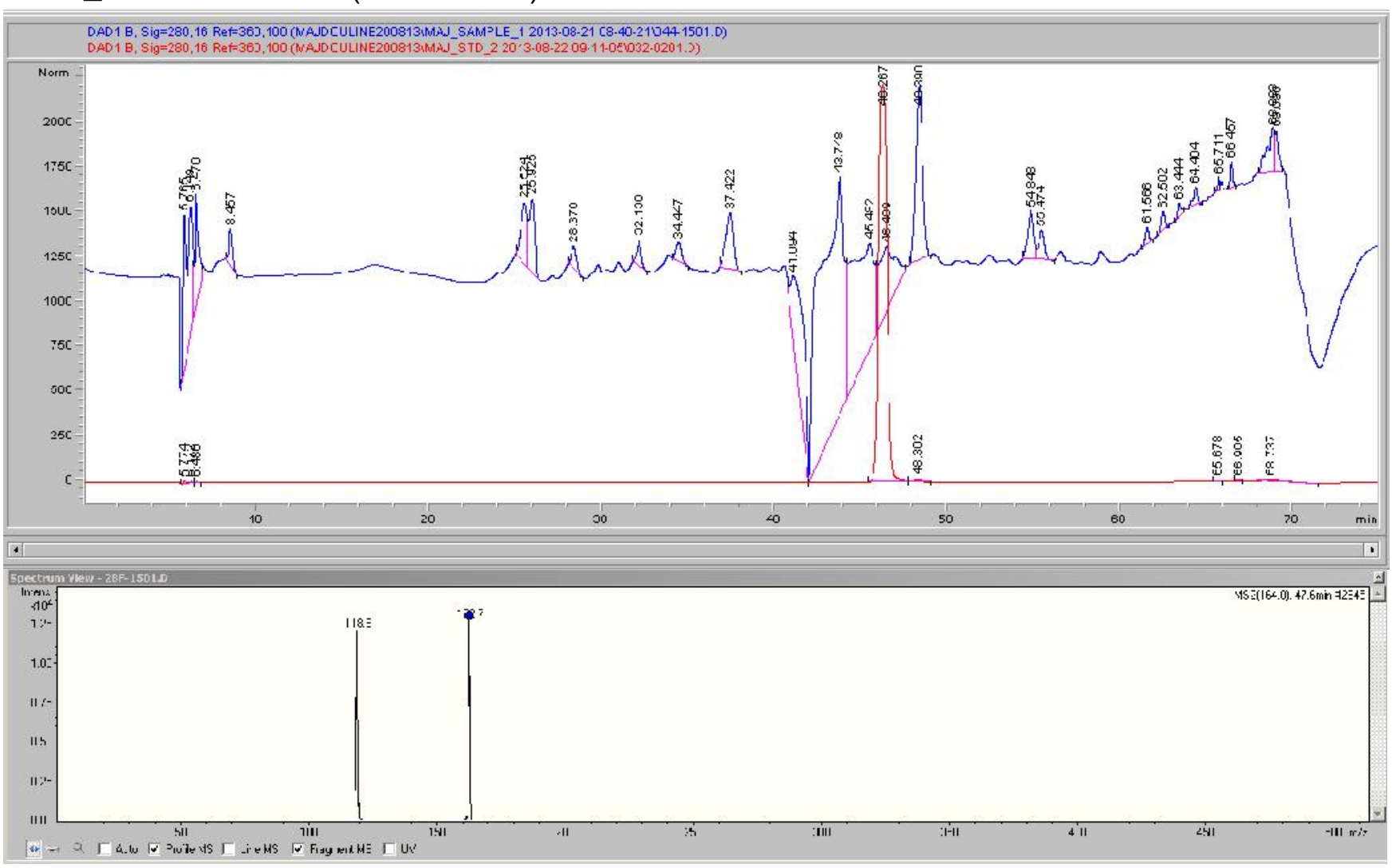


S2F5_hydroxytyrosol (area=1805.63)

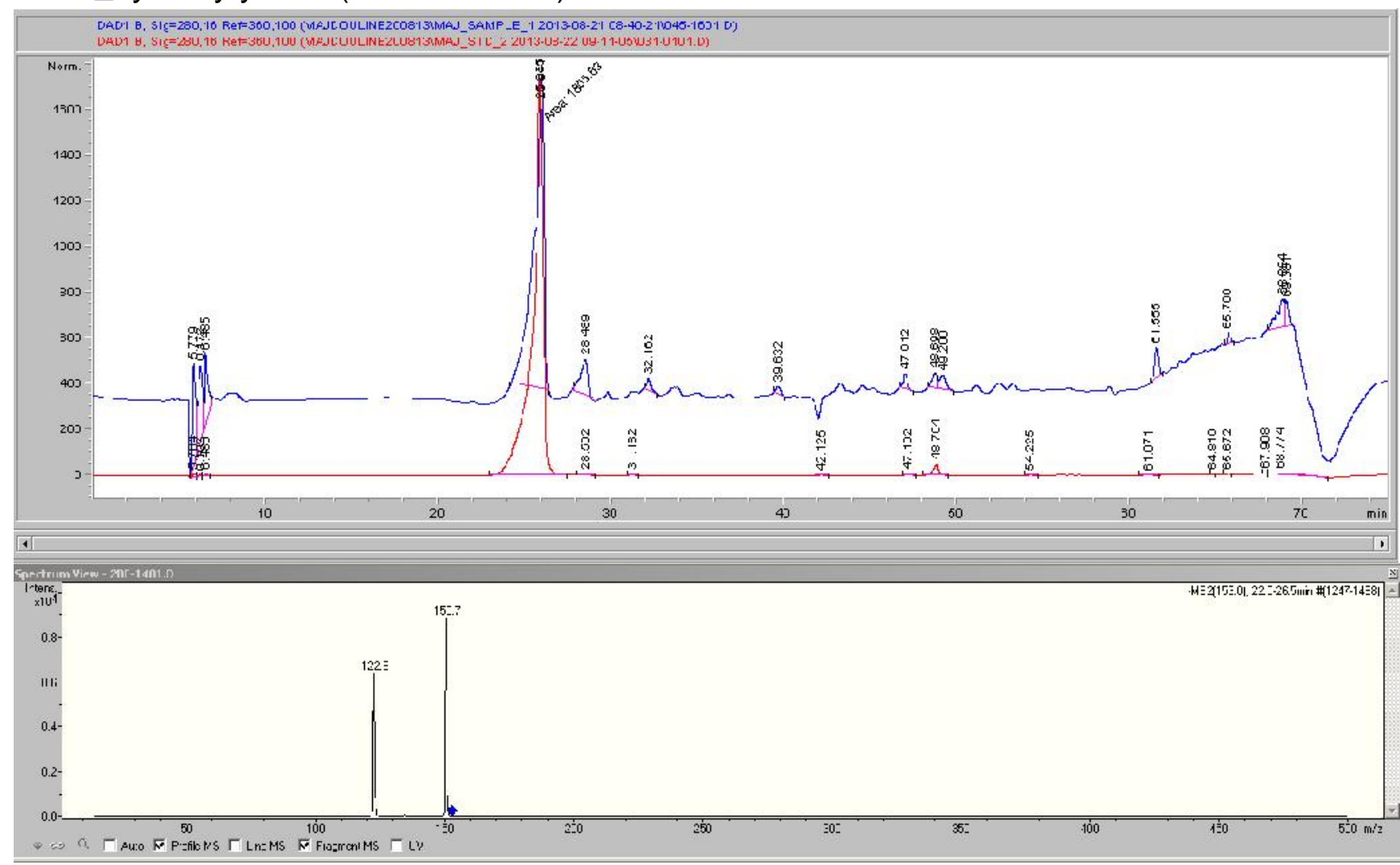

S2F5_oleuropein (area=53.03)

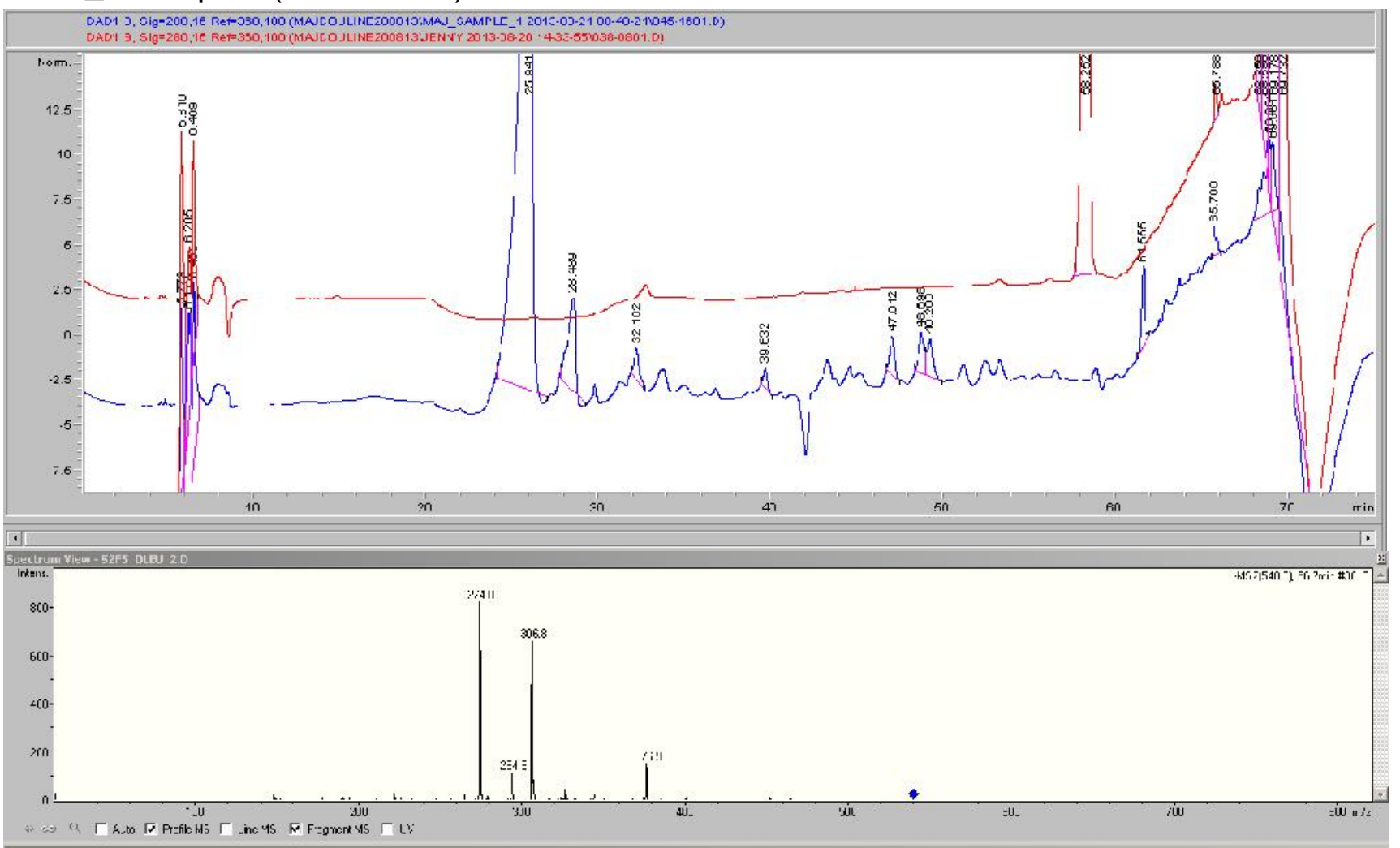


S2F6_hydroxytyrosol (area=325.776)

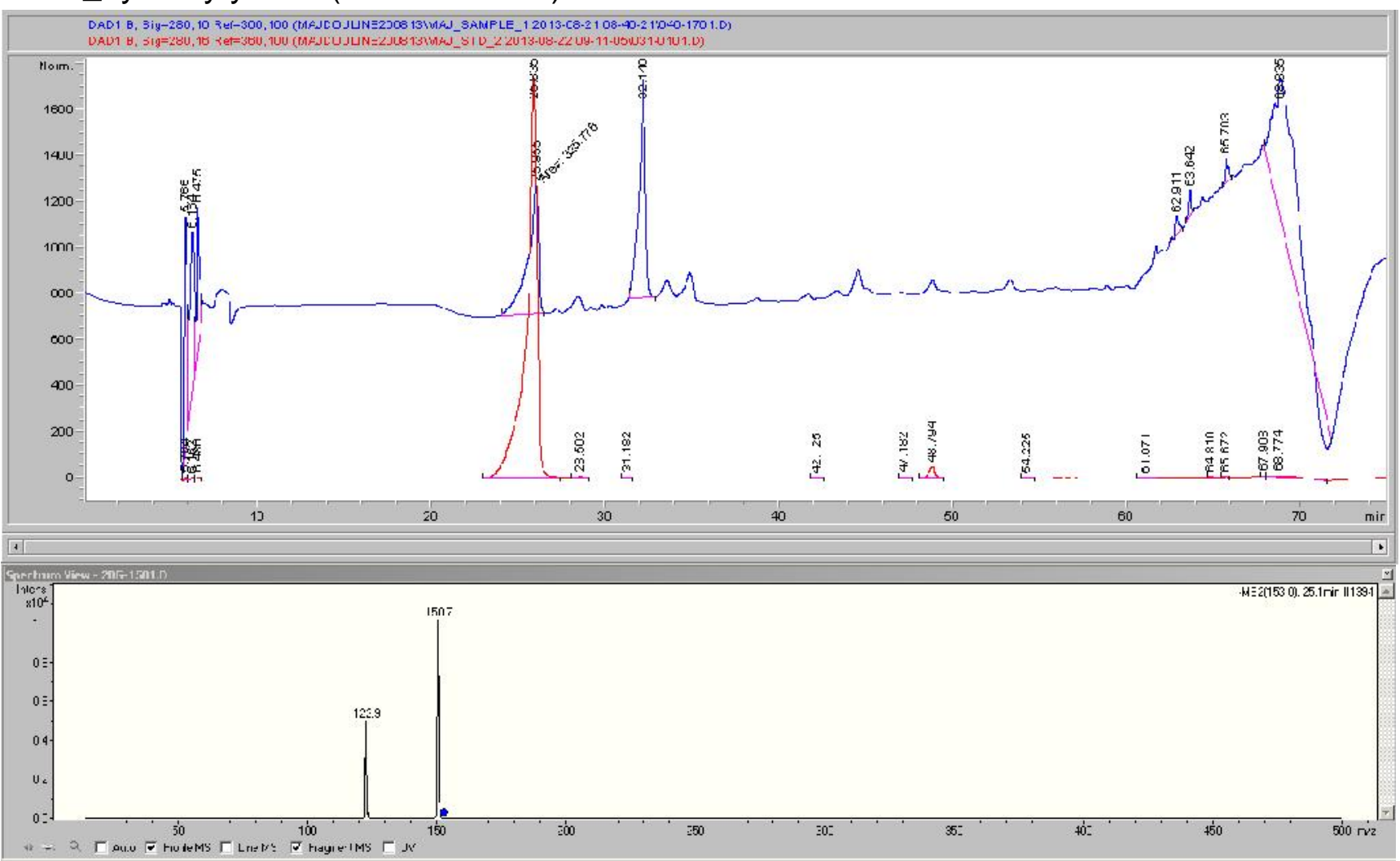

S2F6_Tyrosol (area=378.356)

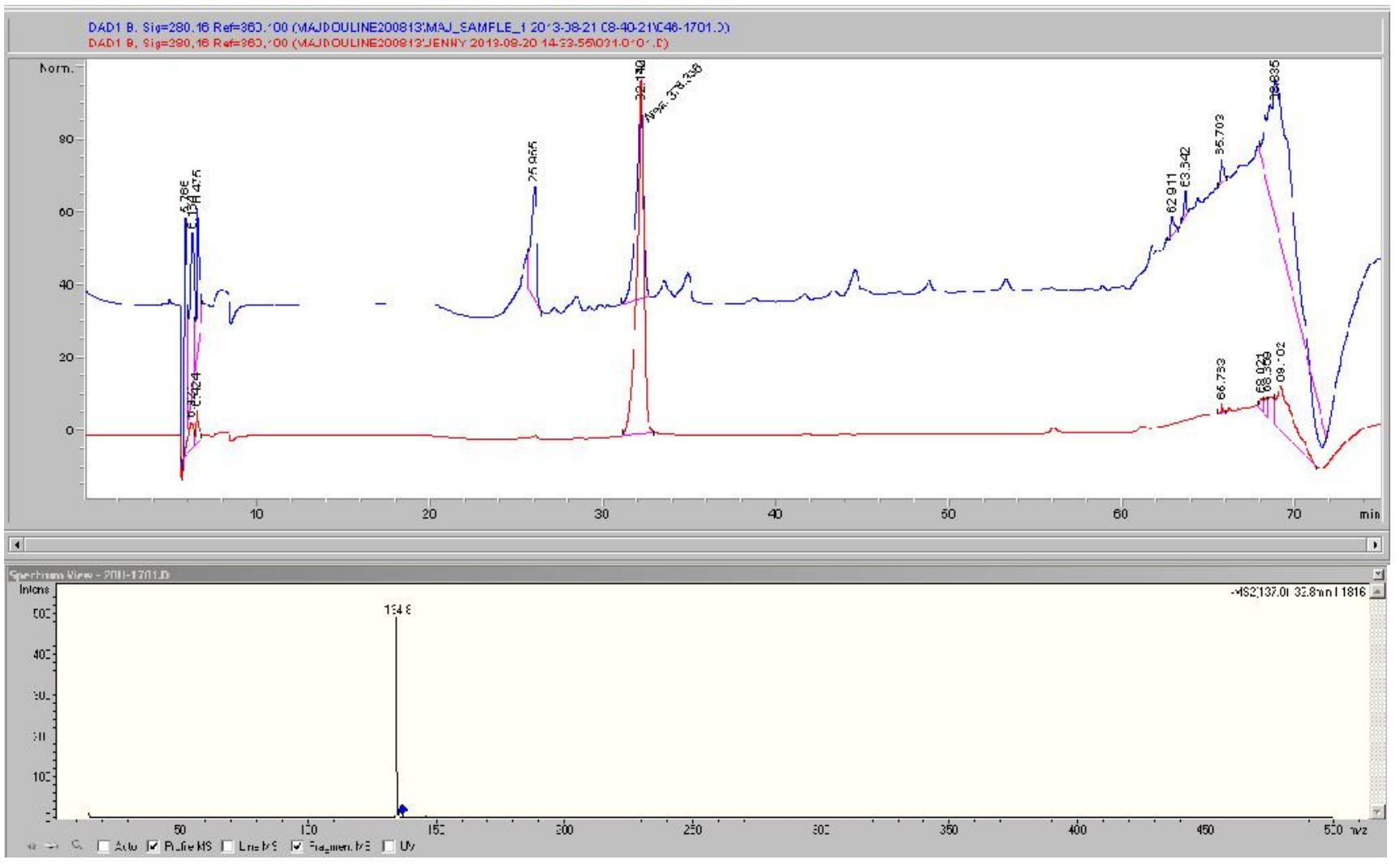


S2F7_tyrosol (area=1859.39)

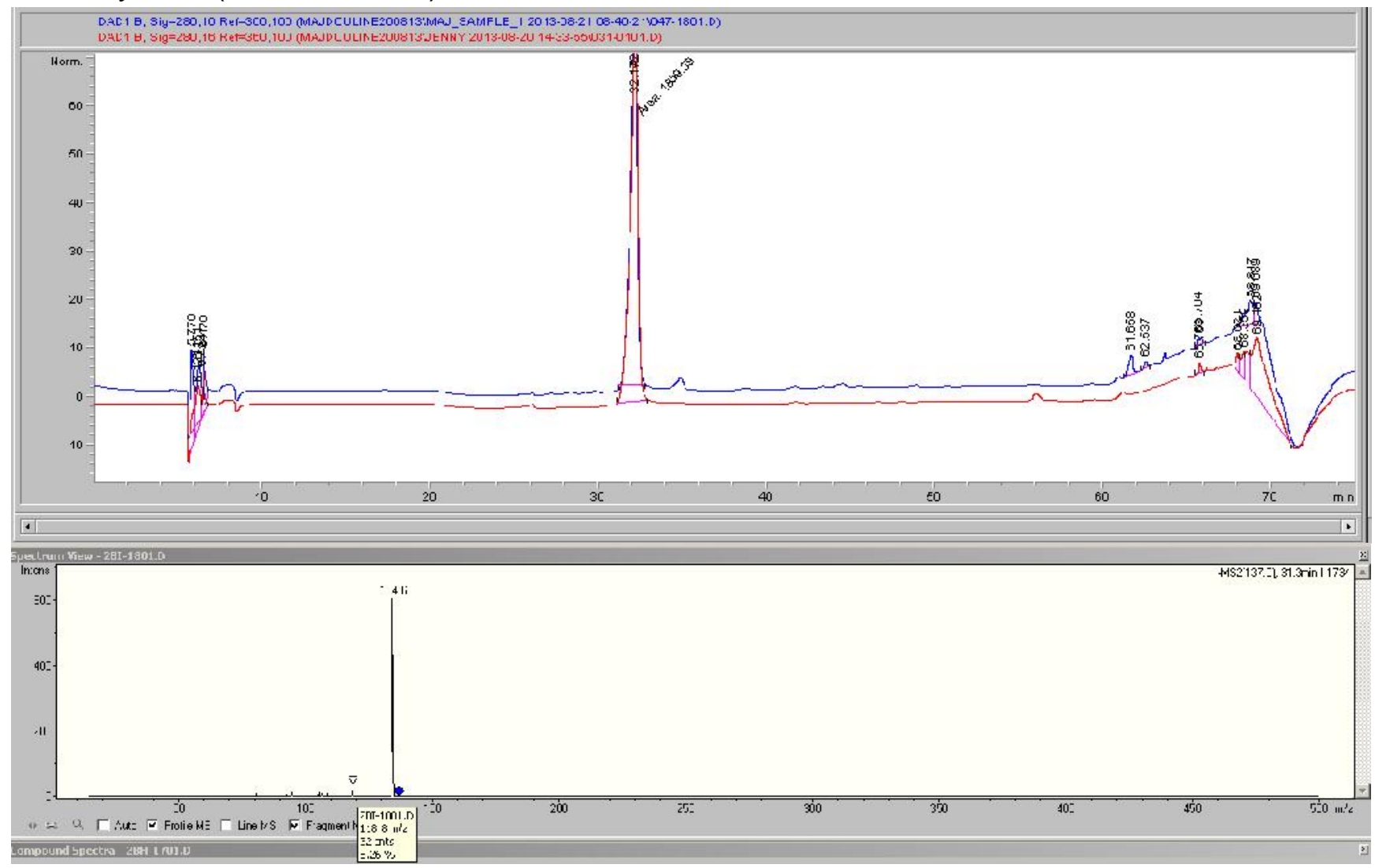

